\title{
BAŞLANGIÇ DÜZEYİ SOLFEJ KİTAPLARI ÜZERİNE BİR İNCELEME
}

A Review on Beginner Level Solfege Books

Siyar KÖKSAL*

\section{ÖZ}

Bir müzik yazısını sesi, süresi ve ölçü yapısına göre okunması anlamına gelen solfej; müziksel işitme, okuma ve yazmanın bir boyutu olarak görüldüğü gibi, müzik teorisinde kazandırılacak olan hedef ve davranışların öğretildiği ve pekiştirildiği bir unsur olarak karşımıza çıkmakta ve bu durumun özellikle başlangıç düzeyinde önemli bir yere sahip olduğu görülmektedir. Eğitimde ders kitabının önemli bir yere sahip olduğu düşünüldüğünde, solfej kitaplarının da bir ders kitabı olarak müzik eğitimi sürecinde önemli olduğu fikri akla gelmektedir. Bu çalışmada; başlangıç düzeyinde kullanılan "Petit Solfege", "Solfége Elémentaire", "Elementary Solfeggi for Medium Voice Op.9”, “Corso Facile di Solfeggio", "Solfége des Solféges 1A ve 1B” solfej kitapları kazandırılacak ya da pekiştirilecek müzik teorisine yönelik konu, ölçü birimi, ton, anahtar ve ses aralığı yönünden sınıflandırılarak incelenmiştir. Araştırmada nitel analiz yöntemlerinden içerik analizi kullanılmış, kitaplarda yer alan solfejler önce kazandırılmaya çalışılan konu yönünden tablolaştırılmış, daha sonra solfejler ölçü birimi, ton, anahtar ve ses aralığı gibi değişkenlerle frekans ve yüzde olarak tablolar halinde yorumlanmıştır. İnceleme sonucunda solfej kitaplarının konu yönünden benzerlikler göstermesine rağmen içerik yönünden farklılaştığı, kitaplarda yer alan solfejlerin eğitimin ilkelerine uygunluk gösterdiği, ölçü birimi noktasında basit ölçü birimlerinin, ton noktasında ise Do majör tonunun tercih edildiği görülmüştür.

Anahtar Kelimeler: Solfej, Solfej Kitapları, Müziksel Okuma, Müzik Teorisi, İçerik Analizi

\begin{abstract}
Solfege, which means to read a musical text according to its sound, duration and measure structure; seen as a dimension of musical hearing, reading and writing, appears as an element in which goals and behaviors to be gained in music theory are taught and reinforced, and this situation seems to have an important place especially at the beginning level. Considering that the textbook has an important place in education, it comes to mind that solfege books are also important as textbooks in music education process. In this study; "Petit Solfege", "Solfége Elémentaire", "Elementary Solfeggi for Medium Voice Op.9”, “Corso Facile di Solfeggio", "Solfége des Solféges $1 \mathrm{~A}$ and 1B" solfege books will be acquired or reinforced. It has been classified and examined in terms of meter, tone, key and pitch. Content analysis, one of the qualitative analysis methods, was used in the study, the solfeges in the books were first tabulated in terms of the subject to be taught, then the solfeges were interpreted in tables in terms of frequency and percentage with variables such as meter, tone, key and pitch. As a result of the examination, it was seen that the solfege books differed in terms of content, although they showed similarities in terms of subject, the solfeges in the books were in accordance with the principles of education, simple metric units were preferred at the point of meter and $\mathrm{C}$ major tone was preferred in terms of key.
\end{abstract}

Keywords: Solfege, Solfege Book, Sight Reading, Musical Theory, Content Analysis

Derleme Makale/Review Article- Geliş Tarihi/Received Date: 18.04.2021 Kabul Tarihi/Accepted Date: 03.06.2021

\footnotetext{
* Sorumlu Yazar/Corresponding Author: MEB İskele Ortaokulu Müzik Öğretmeni, İnönü Üniversitesi Doktora Öğrencisi, koksalsiyar@gmail.com, ORCID ID: 0000-0001-7735-2918
} 


\section{Extended Abstract}

The process of music education emerges as a concept that includes many dimensions, and these dimensions are thought to be related to each other. The alphabet of music, which is a sound art, consists of notes. The basis of music education; as it starts with the teaching of notes, as well as the teaching of theoretical subjects; continues with the teaching process of the pitch between two sounds, the distance between the sounds and the duration of the notes. It is thought that many theoretical gains can be obtained by reading music in the light of the principle of "from music to theory", which is a frequently used principle in general music education.

According to Baş (2015), solfeggio is a mental - physical - musical activity. At the same time, he stated that there are tonal, atonal and maqam note reading exercises that are deliberately read individually and collectively by hearing the notes, the sounds of the notes, their duration, hand strokes, nuance marks, their degrees in the tone and their effective character, and the meanings of the horizontal and vertical intervals in the scale.

Kilıçarslan (1995) stated that the ability to acquire knowledge of music theories, recognize note signs, calculate the proportions of sounds and durations, and use stresses and figures in details is gained through solfege.

While there are various studies on the subject of solfege in the literature, it has been observed that there are also studies on the examination of solfege books used in music education. Ertok (1994), İlkay (2004), Yazan (2007) and Ozan et al. (2017) examined solfege books from various aspects as well as studies on the suitability of solfege books to professional music education.

One of the most important materials of the education process is seen as a textbook. In this context, it can be seen that solfege books have an important place in musical hearing, reading and writing education. It is thought that solfege books should have a rich content in terms of teaching or consolidating notes, intervals, meter, keys and various clefs and other theoretical subjects to music. In this context, it can be seen as an important situation to examine solfege books used in sight reading lessons in institutions providing professional music education as content and to see how the books are systematized in terms of content as a result of the examination.

Considering the importance of the beginner level in the music education process, it is thought that solfege can be an important educational material that enables students to learn by doing, experiencing and seeing. In this context, it is considered important to analyze the solfege at the beginner's level both in terms of the acquisitions (the subject they focus on), in terms of teaching the basic elements in music education such as meter, clef and tone, in terms of their suitability to the vocal ranges of individuals who receive music education as well. In addition, it is the aim and significance of this study to give ideas to researchers, music educators and students at the point of introducing and gaining new resources for the field. In the light of the problem, aim and importance of the research, the problem sentence determined as "What are the features of the beginner solfege books in terms of content?"

The research method is a descriptive research based on content analysis. The works examined in this research are "Petit Solfege" by Edouard Batiste, "Solfége Elémentaire" by Frédéric Boissiére, "Elementary Solfeggi for Medium Voice Op.9" by Gaetano Nava, "Corso Facile di Solfeggio" by Italian composer and pianist Ettore Pozzoli, Adolpe Danhause and "Solfége des Solféges 1A and 1B" written by Henry Lemoine, compiled from various works and classified by Albert Lavignac.

As a result of the findings obtained in the research; 
- Solfege books showed similarity in terms of subjects and differed in terms of content,

- Solfege books are systematized in the light of the principles of education,

- In the books, 2/4, 3/4 and 4/4 meters are mostly used.

- The C major key is used intensively.

- It has been concluded that in solfege books where more than one clef is taught, generally solfege in treble clef is common, and some solfege books consist only of exercises in treble clef.

Based on the results of the research suggestions such as increasing metric and tonal diversity, adding alto clef solfege to give ideas apart from the treble clef and bass clef, expressing theoretical information in writing before solfege, examining solfege books written on Turkish music in terms of makam and method, examining different beginner level books and advanced solfege books were given. 
Müzik eğitimi süreci kendi içerisinde birçok boyutu barındıran bir kavram olarak karşımıza çıkmakta ve bu boyutların birbiriyle ilişkili olduğu düşünülmektedir. Bir ses sanatı olan müziğin alfabesi notalardan oluşmaktadır. Müzik eğitiminin temeli; teorik noktada notaların öğretimiyle başladığı gibi, iki ses arasındaki yüksekliğin, sesler arasındaki mesafenin ve nota sürelerinin öğretimi süreciyle devam etmekte ayrıca teorik konuların öğretimi de yapılmaktadır. Genel müzik eğitiminde sıklıkla başvurulan bir ilke olan "müzikten teoriye” ilkesi 1şı̆̆ında birçok teorik ve duyuma yönelik kazanımın müziksel okuma yoluyla kazandırılabileceği düşünülmektedir.

Fransızca "Solfej” (Aydoğan, 1998) olarak isimlendirilen müziksel okuma; Müziğin harfleri olarak nitelendirilebilecek notaları; isim, süre, ses yüksekliği, hız, gürlük, figür ve ayrıntılarıyla seslendirilmesiyle yapılan; zihinde tonun, aralıkların ve aralıklarla birlikte ana ve yan derecelerin uygulandığı vokal ve işitme çalışmaları olarak tanımlanmıştır (Erol, 2019; Ertok, 1994; Kılıçarslan, 1995; Özçelik, 2010; Özgür ve Aydoğan, 2015). Baş (2015) zihinsel - bedensel - müziksel bir aktivite olarak vurguladığı solfeji, müziksel sesleri, isimleri, süresi, el vuruşları, nüans işaretleri, ton içindeki dereceleri ve etkisel karakteri ile yatay ve dikey aralıkların dizi içindeki anlamlarını duyarak - bilerek bireysel ve toplu olarak okunan tonal, atonal ve makamsal nota okuma çalışmaları olduğunu belirtmiştir.

Müzik öğretiminde atılacak ilk adımın, bu sanat dalına ilişkin temel bilgileri iyi kavramak olduğu kuşkusuzdur. İyi duyan bir kulak, notaları hızlı okuyan gözler ve şaşmaz bir ritim duygusu, müzik tekniğinin temelidir. "Solfej”, kulağımızın, gözümüzün ve reflekslerimizin gelişimini sağlar. Bu reflekslerin tümüne '“akıl tekniği”' (Tecniqune mentale) diyoruz. Böyle bir tekniği edinemeyen müzikçi, sanatının ilk güçlüklerini bile yenemez. Bundan ötürü, “küçük yaştan başlayarak solfeje önem vermek', öğrenciden iyi sonuç almak isteyen her öğretmene önerilmektedir (Fenmen, 1997).

Kılıçarslan (1995) Solfeji; müzik öğretiminin temel eğitimlerinden biri olduğunu; müzik kuramları bilgisi edinme, nota işaretlerini tanıma, seslerin ve sürelerin oranlarını hesaplama, vurguları ve figürleri ayrıntılar halinde kullanabilme becerilerinin solfej ile kazanıldığını belirtmiştir.

Tanımlardan hareketle solfej, dizek üzerinde çeşitli türlerde anahtarlarla yazılmış olan notaları ve eserleri ses, süre değerleri, aralık, hız, ton ve nüanslarıyla okuma veya okuma davranışı kazandırma olarak tanımlandığı gibi müzik teorisine yönelik kavramlarında öğretildiği veya pekiştirildiği vokal çalışmalar olarak tanımlanabilir.

Ünlü'ye (2019) göre solfej eğitimi, müzik eğitiminin her türünde eğitim alan bireylerin müzik eğitiminin boyutlarına katkı sağlayarak onların müziksel olarak gelişmelerine yardımcı olduğu düşünülmektedir. Yazan (2007) müzik eğitiminde önemli bir yere sahip olan solfej eğitiminin; müziksel işitme, okuma, yazma ve müzik teorisi konularını kapsadığını, müzik yapan bireylere gerekli olan temel müziksel davranışların solfej yoluyla kazandırmasının amaçladığını belirtmiştir.

Literatürde solfej konusu üzerine çeşitli çalışmaların olduğu görülürken, müzik eğitiminde kullanılan solfej kitaplarının incelenmesi konusunda da çalışmaların olduğu görülmüştür. Ertok (1994) cumhuriyet döneminden itibaren ülkemizde yazılmış solfej kitaplarını incelediği görülmüştür. İlkay (2004) müzik öğretmenliği bölümlerinde okutulan Albert Lavignac tarafından hazırlanan Solfége des Solféges 1A, 1B, 2A, 2C, 3A kitaplarını, Ülkü Özgür ve Salih Aydoğan tarafından yazılmış olan “Müziksel İşitme Okuma 1'inci kitap” ve Sadık Özçelik tarafından yazılmış olan “Müzikal Dikte ve Solfej” kitapları ses aralığı, anahtar, ölçü birimi parametreleri üzerine 
nicel bir inceleme yapmıştır. Yazan (2007) konservatuarların şan programında uygulanan solfej eğitiminde izlenen kaynak ve yöntemleri analiz ettiği görülmüştür. Ozan vd. (2017) çoksesli solfej eğitiminde kullanılan Albert Lavignac tarafindan hazırlanan Solfége des Solféges 6A, 6B, 7A, 7B, 8A, 8B, 9A ve 9B kitaplarını çokseslilik durumuna, tonal yapılarına, ölçü birimlerine, hız terimlerine, anahtar yapısına ve ses aralıklarına göre inceldikleri görülmüştür.

Eğitim öğretim sürecinin en önemli materyallerinden biri de ders kitabı olarak görülmektedir. Bu bağlamda müziksel işitme, okuma ve yazma eğitiminde solfej kitaplarının önemli bir yer tuttuğu görülebilir. Solfej kitaplarının notaları, aralıkları, ölçü birimlerini, tonları ve çeşitli anahtarları vb. teorik konuları öğretme veya pekiştirme noktasında zengin bir içeriğe olması gerektiği düşünülmektedir. Bu bağlamda mesleki müzik eğitimi veren kurumlarda müziksel okumaya yönelik derslerde kullanılan solfej kitaplarının içerik olarak incelenmesi ve inceleme sonucunda kitapların içerik noktasında nasıl sistematize edildiğinin görülmesi önemli bir durum olarak görülebilir.

Yapılan çalışmalarda, kitaplarda yer alan solfejlerin ölçü, ton, anahtar, ses aralığı vb. değişkenlerin nicel olarak durumlarına değinilse de; solfejlerin odaklandığı, kazandırmaya veya pekiştirmeye çalıştığı temel teorik konulara değinilmediği görülmüştür. Müzik eğitimi sürecinde başlangıç düzeyinin önemi düşünüldüğünde solfejlerin öğrenciye yaparak, yaşatarak ve görerek öğrenmesini sağlayan önemli bir eğitim materyali olabileceği düşünülmektedir. Bu bağlamda başlangıç düzeyinde yer alan solfejlerin hem kazandırmaya çalıştığı içerik (odaklandığı konu) yönünden hem ölçü, anahtar, ton gibi müzik eğitiminde yer alan temel öğeleri öğretmesi yönünden hem de müzik eğitimi alan bireylerin ses aralıklarına uygunluğu yönünden analiz edilmesi önemli görülmektedir. Ayrıca alana yönelik yeni kaynakların tanıtılması ve kazandırılması noktasında araştırmacılara, müzik eğitimcilerine ve öğrencilere fikir vermesi bu çalışmanın amacını oluşturmakta ve bu amaç ışığında alana faydalı olacağı düşünülmektedir. Araştırmanın problemi, amacı ve önemi 1şı̆̆ında problem cümlesi "Başlangı̨̧ düzeyi solfej kitapları içerik yönünden özellikleri nasıldır?” olarak belirlenmiş ve bu temel problem çerçevesinde aşağıda yer alan sorulara yanıt aranmıştır;

1) Solfej kitaplarında öğretilecek veya pekiştirilecek teorik konular nasıl sistematize edilmiştir?

2) Solfej kitaplarında yer alan solfejlerin ölçü birimi yönünden oluşumu nasıldır?

3) Solfej kitaplarında yer alan solfejlerin ton yönünden oluşumu nasıldır?

4) Solfej kitaplarında yer alan solfejlerin anahtar yönünden oluşumu nasıldır?

5) Solfej kitaplarında yer alan solfejlerin ses aralı̆̆ yönünden oluşumu nasıldır?

\section{Yöntem}

\section{Araştırmanın Modeli}

Araştırma; içerik analizine dayalı betimsel bir araştırmadır. Büyüköztürk vd. (2015) betimsel araştırmayı; verilen bir durumun olabildiğince tam ve dikkatli bir şekilde tanımlandığı araştırmalar olduğunu belirtirken; içerik analizini; belirli kurallara dayalı kodlamalarla bir metnin bazı sözcüklerinin daha küçük içerik kategorileriyle özetlendiği sistematik, yenilenebilir bir teknik olarak tanımlamıştır. Best ve Kahn (2017) ise bir olayın belirli zamandaki konumunun ya da zaman içinde geçirdiği değişimleri açıklamalarıyla ilgili olduğunu belirterek veri kaynağı olarak kayıtlar, raporlar, akademik çalışmalar, kitaplar, süreli yayınlar bültenlerin kullanılabileceğini belirtmiştir. 


\section{Çalışma Grubu}

Araştırmanın çalışma grubunu başlangıç düzeyinde bulunan 8 solfej kitabı oluşturmuştur. Solfej kitapları seçilirken içerikleri incelenmiş ve içeriğinde teorik konulara yönelik açıklamalar bulunan veya mesleki müzik eğitiminde kullanılabilirliğe sahip olan solfej kitaplarının çalışma grubuna dâhil edilmesine karar verilmiştir. Çalışma grubunda yer alan solfej kitapları, yazarları, solfej sayısı ve menşei tablo 1'de gösterilmiştir.

Tablo 1. Araştırmanın çalışma grubunu oluşturan solfej kitaplart

\begin{tabular}{|c|c|c|c|}
\hline Solfej Kitab1 & Yazar & Solfej Sayısı & Basıldığı Ülke / Şehir \\
\hline Petit Solfége & Edouard Batiste & 100 & Fransa / Paris \\
\hline Solfége Elémentaire & Frédéric Boissiére & 110 & Fransa / Paris \\
\hline Elementary Solfeggi for the Medium Voice Book1 & & 50 & ABD / New York \\
\hline Elementary Solfeggi for the Medium Voice Book2 & Gaetano Nava & 30 & $\mathrm{ABD} / \mathrm{New}$ York \\
\hline Elementary Solfeggi for the Medium Voice Book3 & & 17 & $\mathrm{ABD} / \mathrm{New}$ York \\
\hline Corso Facile di Solfeggio & Ettore Pozzoli & 190 & İtalya / Milano \\
\hline Solfége des Solféges $1 \mathrm{~A}$ & Albert Lavignac & 204 & Fransa / Paris \\
\hline Solfége des Solféges 1B & Albert Lavignac & 168 & Fransa / Paris \\
\hline
\end{tabular}

Araştırmanın çalışma grubunu oluşturan 8 solfej kitabı incelendiğinde; "Elementary Solfeggi for Medium Voice” solfej kitabının kendi içerisinde 3 farklı kitaptan oluştuğu görülmüştür. Kitaplar arasındaki en çok solfejin "Solféges de Solféges 1A" kitabında olduğu görülürken, en az solfejin "Elementary Solfeggi for Medium Voice Book 3" solfej kitabında olduğu görülmüştür. 8 kitabın 4'ünün Fransa'da basıldığı görülürken, sadece 1 kitabın İtalya'da basıldığı görülmüştür.

\section{Verilerin Toplanması ve Analizi}

Araştırmada solfej kitapları ilk etapta içerik olarak incelenmiş; kitaplarda yer alan solfejlerin müzik teorisinde hangi konuyu veya konuları öğrettiği ya da pekiştirdiği tespit edilmiştir. Kitaplarda yer alan solfejler Microsoft Excel programında ölçü birimi, ton, anahtar ve ses aralığı değişkenlerine göre sınıflandırılmış; solfejlerin müzik teorisinde hangi konuya odaklandığı, ilgili solfejin olduğu satırda belirtilmiştir. Sınıflandırma işleminden sonra SPSS 22.1 programı ile solfejlerin betimsel istatistikleri yapılarak tablolaştırılmış ve yorumlanmıştır.

Bunun dışında çalışma grubunda yer alan kitaplardaki solfejler ses aralıkları yönünden de incelenmiş, solfejlerin bulundukları oktavlar numaralandırılmıştır. Bu bağlamda piyanoya göre kontur oktav 1, büyük oktav 2, küçük oktav 3, birinci oktav 4, ikinci oktav 5 olarak numaralandırılmıştır.

\section{Bulgular ve Yorumlar}

\section{Birinci Alt Probleme Yönelik Bulgular ve Yorumlar}

“Solfej kitaplarında öğretilecek veya pekiştirilecek teorik konular nasıl sistematize edilmiştir?” alt problemine yönelik bulgular ve yorumları her solfej kitabı ayrı ayrı incelenerek solfej numarası, odaklandığı konu ve varsa açıklama şeklinde tablo şeklinde gösterilmiştir. 
Edouard Batiste "Petit Solfége" Solfej Kitabı. Edouard Batiste tarafinda yazılan "Petit Solfege" isimli kitapta toplam 100 tane solfejin olduğu görülmüş ve solfejlerin odaklandığı konular tablo 1 'de gösterilmiştir.

Tablo 2. "Petit Solfege" solfej kitabının odaklandığı konular ve açıklamaları

\begin{tabular}{|c|c|c|}
\hline $\begin{array}{c}\text { Solfej } \\
\text { Numarası }\end{array}$ & Odaklandığı konu ve konular & Açıklama \\
\hline $1-18$ & Aralık çalışmaları & 2'li, 3'lü, 4'lü, 5'li, 6'lı, 7'li, 8'li, 9'lu ve 10'lu aralıklar \\
\hline $19-20$ & Noktalı tartımlar & \\
\hline $21-24$ & Kromatik gamlar & \\
\hline $25-26$ & Senkop & \\
\hline $27-28$ & Üçleme & \\
\hline $29-30$ & Minör tonlar & La minör tonu \\
\hline $31-32$ & Minör tonlar - 3/4 ve 3/8'lik Ölçüler & Aynı solfej $3 / 4^{\prime}$ lük ve $3 / 8^{\prime}$ 'lik varyasyonu mevcut \\
\hline $33-34$ & Majör ve minör tonlarda dizi çalışmaları & \\
\hline $35-47$ & Modülasyon & $\begin{array}{l}\text { Do majör ve La minör tonlarında uzak ve yakın tonlara } \\
\text { modülasyon }\end{array}$ \\
\hline $48-54$ & Genel alıştırma & Şu ana kadar ki tüm konular \\
\hline $55-58$ & Majör ve minör tonlarda akorlar, tonalite ve kadanslar & \\
\hline $59-63$ & Nüans terimleri & Öncesinde disonans ve konsonans akorlara değinilmiş \\
\hline $64-74$ & Genel Alıştırma & Sol Majör ve Mi Minör tonlarda çalışmalar \\
\hline $75-77$ & Tekrar işareti & Tekrar işareti, dolap, senyö \\
\hline $78-81$ & 9/8'lik ölçüler ve majör minör ton çalışmaları & Mi bemol majör, do minör, La majör, Fa\# minör \\
\hline $82-83$ & 3/8'lik ölçüler & La bemol majör fa minör \\
\hline $84-87$ & Majör ve minör tonlar & Mi majör, Re bemol majör, Si majör \\
\hline 88 & Anarmonikler & \\
\hline 89 & 3/2'lik ölçüler ve majör minör tonlar & Sol bemol majör \\
\hline $90-91$ & Tüm dizilerde Fa anahtarı çalışmaları & \\
\hline $92-100$ & Fa anahtarında genel alıştırmalar & \\
\hline
\end{tabular}

Fransız besteci Eduardo Batiste tarafından yazılan "Petit Solfege” isimli solfej kitabı; ilk girişte dizek, nota yerleri, nota - sus değerlerinin ve hız terimlerinin anlatımıyla başlamaktadır. Daha sonra aralıklar (2'li, 3'lü, 4'lü, 5'li, 6'lı, 7'li, Oktav, 9'lu ve 10'lu aralıklara) konusuna yönelik çalışmalar mevcuttur. Kitapta yer alan alıştırmaların odaklandığı konular ise sırasıyla; Noktalı tartımlar, senkop, üçleme, majör - minör tonlar ve 3/4 -3/8'lik ölçüler, modülasyon, majör akorlar ve tonalite, majör ve minör tonlarda kadans, nüans terimleri, tekrar işaretleri, 9/8'lik ölçüler ve ton çalışmaları, 3/2'lik ölçüler ve ton çalışmaları, Fa anahtarında dizi çalışmaları ve Fa anahtarında alıştırmalar şeklindedir ve bazı solfejlerin birden fazla konuya odaklandığı görülmüştür. Ayrıca belirli konulardan sonra daha önceki konuları pekiştirmeye yönelik genel alıştırmalar da mevcuttur.

Frédéric Boissiére "Solfége Elémentaire" Solfej Kitabı. Frédéric Boissiére tarafından yazılan "Solfége Elémentaire" solfej kitabında 110 adet solfej olduğu görülmüştür. Kitaptaki solfejlerin odaklandığı konular tablo 3'te açıklamaları ile gösterilmiştir.

Tablo 3. "Solfége Elémentaire" solfej kitabının odaklandığı konular ve açıklamaları

\begin{tabular}{c|c|c}
\hline $\begin{array}{c}\text { Solfej } \\
\text { Numarası }\end{array}$ & Odaklandığı konu ve konular & Açıklama \\
\hline $1-4$ & Notalar ve entonasyon çalışmaları & \\
\hline $5-18$ & Aralık çalışmaları & 2'li, 3'lü, 4'lü, 5'li, 6'lı, 7'li, 8'li aralıklar \\
\hline $19-20$ & Genel alıştırma & Aralıklarla ilgili \\
\hline 21 & Aralık çalışmaları & 9'lu ve 10'lu aralıklar \\
\hline $22-23$ & 3/4'lük ölçüler ve çoğaltma noktası & \\
\hline
\end{tabular}




\begin{tabular}{|c|c|c|}
\hline $24-27$ & Değiştirici işaretler & \\
\hline $28-31$ & 2/4'lük ölçüler & \\
\hline $32-35$ & Tekrar ve dönüş işaretleri & Röpriz, dolap, senyö, de capo \\
\hline 36 & Kromatik gamlar & \\
\hline $37-39$ & La minör & \\
\hline $40-53$ & Majör tonlar & Sol majör, Fa majör, Re majör, Si bemol majör \\
\hline $54-59$ & Senkop ve bağ & \\
\hline $60-67$ & Minör tonlar & Mi minör, Re minör \\
\hline 68 & Noktalı sus işaretleri & \\
\hline $69-72$ & Üçleme & $\begin{array}{c}\text { Üç 8'lik notadan oluşan üçleme dışında, Bir 8'lik sus } \\
\text { ve iki notalı üçleme ve bir 4'lük, bir 8'likten oluşan } \\
\text { üçleme }\end{array}$ \\
\hline 73 & Nüans terimleri / Minör tonlar & Si minör \\
\hline $74-78$ & 16'llk notalar & Genel konu tekrarı içeriyor \\
\hline 79 & Çarpma & \\
\hline 80 & Puandorg & \\
\hline $81-82$ & Eksik ölçü & \\
\hline $83-85$ & Çift çoğaltma noktası / Minör tonlar & Sol minör \\
\hline $88-89$ & 6/8'lik ölçüler / Majör tonlar & La majör \\
\hline $90-91$ & 9/8'lik ölçüler & \\
\hline $92-93$ & Minör tonlar & Fa\# minör \\
\hline $94-95$ & 12/8'lik ölçüler & \\
\hline $96-97$ & Majör tonlar & Mi bemol majör \\
\hline $98-99$ & 3/8'lik ölçüler & \\
\hline $100-101$ & Minör tonlar & Do minör \\
\hline $102-103$ & 2/2'lik ölçüler & \\
\hline $104-105$ & 3/2'lik ve 4/2'lik ölçüler & $\begin{array}{l}\text { Bu konudan sonra 5/4'lük, 6/4'lük, 2/16'lık 4/16'lık } \\
\text { gibi az kullanılan ölçüler konusuna değinilmiş }\end{array}$ \\
\hline $106-107$ & Çift diyez, çift bemol & \\
\hline $108-110$ & Legato ve detache & \\
\hline
\end{tabular}

Fransız besteci Frédéric Boissiére tarafından yazılan solfej kitabının notalar ve entonasyon konuları ile başladığı görülmektedir. Notalar ve entonasyon çalışmalarından sonra, 2'li aralıklardan 10'lu aralıklara kadar aralık konularının işlendiği; 8'li aralıklardan sonra aralık konusunun pekiştirilmesi amacıyla yazılmış olan genel alıştırmalar olduğu görülmüştür. Aralık konularından sonra 3/4'lük ölçüler ve bu konu ile bağlantılı çoğaltma noktası konusuna yönelik solfejlerin olduğu tespit edilmiştir. Değişstirici işaretler, 2/4'lük ölçüler, kromatik gamlar konularından sonra majör tonlar işlenmiştir, bu konudan önceki tüm solfejlerin Do majör tonunda yazıldığı görülmüştür. Ayrıca majör tonlar konusunda daha zengin ezgilerle solfej çalışmalarının yapılmaya çalışıldığı majör gamlar konusunun önceki konuları pekiştirebilecek nitelikte solfejlerden oluştuğu tespit edilmiştir. La minör tonun başlı başına bir konu olarak işlendiği, bu şekilde minör ezgilerin nasıl duyulabileceğine yönelik öğrencide fikir oluşturması amaçlandığı düşünülmüştür. Sonraki konular incelendiğinde; senkop ve bağ, üçleme, nüans terimleri konusuna yönelik solfejlerin olduğu, nüans terimleri konusu içerisinde minör tonlara yönelik çalışmaların başladığı tespit edilmiştir. 16'lık notalar konusunun ayrıca genel tekrar niteliği taşıdığı, bu konudan sonra süsleme ve ifade terimlerinin başladığı da görülmüştür. $\mathrm{Bu}$ konudan sonra eksik ölçü konusunun başladığı ve her solfejin birden fazla konuyu ele aldığı tespit edilmiştir. Sonlara doğru 3/2, 4/2, 5/4, 6/4, 2/16, 4/16 gibi az kullanılan ölçü birimlerine yönelik çalışmaların da olduğu görülmüştür. 
Gaetano Nava "Elementary Solfeggi for Medium Voice Op.9” Solfej Kitabı. Gaetano Nava tarafindan yazılan "Elementary Solfeggi for Medium Voice Op.9" solfej kitabı kendi içerisinde üç farklı kitabı içermektedir. Birinci kitapta 50, ikinci kitapta ilk 10’’u egzersiz niteliğinde toplam 30, üçüncü kitapta ise 17 solfej olduğu görülmüştür. Kitapta yer alan solfejler açıklamaları ile birlikte tablo 4 'te gösterilmiştir.

Tablo 4. “Elementary Solfeggi for Medium Voice Op.9” solfej kitabının odaklandığı konular ve açıklamaları

\begin{tabular}{|c|c|c|}
\hline $\begin{array}{c}\text { Solfej } \\
\text { Numarası } \\
\end{array}$ & Odaklandığı konu ve konular & Açıklama \\
\hline \multicolumn{3}{|l|}{ Birinci Kitap } \\
\hline $1-3$ & 1'lik, 2'lik, 4'lük notalar ve ses entonasyonu çalışmaları & \\
\hline $4-6$ & Genel alıştırma & 1'lik, 2'lik ve 4'lük notalara yönelik \\
\hline 7 & 8'lik notalar & \\
\hline $8-9$ & Genel alıştırma & 1'lik, 2'lik, 4'lük, 8'lik notalara yönelik \\
\hline 10 & Diyez - Bemol & \\
\hline 11 & Nüans terimleri & Piano, Cressendo, Decressendo \\
\hline 12 & Diyez - Bemol - Natürel & \\
\hline 13 & Staccato - Legato & \\
\hline $14-16$ & Genel alıştırma & \\
\hline $17-23$ & 4'lük ve 8'lik sus & \\
\hline $24-26$ & Genel alıştırma & \\
\hline $27-34$ & $2 / 4,6 / 8,3 / 4,3 / 8,9 / 8$ ölçüler & \\
\hline $35-36$ & 16'lik notalar & \\
\hline $37-38$ & Genel alıştırma & \\
\hline $39-42$ & Uzatma noktası ve çift uzatma noktası & \\
\hline $44-46$ & Senkop ve bağ & \\
\hline $47-48$ & Üçleme ve altılama & \\
\hline $49-50$ & 32'lik notalar & \\
\hline \multicolumn{3}{|l|}{ İkinci Kitap } \\
\hline $\operatorname{Ex} 1-\operatorname{Ex} 10$ & Aralıklar & $\begin{array}{l}\text { Diatonik dizilerde aralıklar - bölümde yer alan } \\
\text { solfejlerden bağımsız çalışmalar }\end{array}$ \\
\hline $1-20$ & Genel alıştırma & Aralıklarla ilgili çalışmalar \\
\hline \multicolumn{3}{|l|}{ Üçüncü Kitap } \\
\hline $1-8$ & Genel alıştırma & \\
\hline $9-17$ & Süslemeler ve süslemelerle ilgili alıştırmalar & $\begin{array}{l}\text { Tek nota, çift nota apajetür, üç nota ve dört nota } \\
\text { grupetto ve trill }\end{array}$ \\
\hline
\end{tabular}

Birinci kitabın 50 solfejden oluştuğu ve bu solfejlerin notalar, nota süre ve değerleri, 2/4, 3/4, 6/8, 12/8 ölçüler, diyez ve bemol, staccato ve legato, uzatma bağı, çoğaltma noktası, üçleme ve altılama gibi konulara ve bu konuların pekiştirilmesi için yazılmış olan genel alıştırmalardan oluştuğu görülmüştür. İkinci kitabın ilk 10 solfejin aralık öğretimine odaklanmış bağımsız solfejlerden oluştuğu, sonrasında yer alan 20 solfejin ise aralıklar konusunu pekiştirmeye yönelik genel alıştırmalar olduğu tespit edilmiştir. Üçüncü ve son kitap ise birinci ve ikinci kitaplardaki konuları pekiştiren genel alıştırmalarla başladığı ve sonrasında süslemeler konusuna odaklandığı görülmüştür. Kitapta tonalite kavramının öğretimi için ayrı bir konu olmadığı tespit edilmiştir.

Ettore Pozzoli “Corso Facile di Solfeggio” Solfej Kitabı. İtalyan besteci ve piyanist Ettore Pozzoli tarafından hazırlanan bu solfej kitabı hem özgün hem de farklı müzik tarihi dönemlerinden besteciler tarafından bestelenmiş concone biçiminde eserler ile çok sesli koro ve orkestra eserlerinin ses ve çalgı partilerinden oluşan toplam 190 solfejden oluştuğu görülmüştür. Kitapta yer alan solfejlerin odaklandığı konular açıklamaları ile birlikte tablo 5 'te gösterilmiştir. 
Tablo 5. “Corso Facile Di Solfeggio” solfej kitabının odaklandı̆̆ı konular ve açıklamaları

\begin{tabular}{|c|c|c|}
\hline $\begin{array}{c}\text { Solfej } \\
\text { Numarası }\end{array}$ & Odaklandığı konu ve konular & Açıklama \\
\hline $1-21$ & $2 / 4,3 / 4,4 / 4$ ölçüler ve entonasyon çalışmaları & $\begin{array}{l}6 \text { numaralı solfejin tek varyasyonu bulunurken, } 16 \\
\text { numaralı solfejin } 4 \text { farklı varyasyonu mevcuttur. }\end{array}$ \\
\hline $22-27$ & 3'lü, 4'lü aralıklar & \\
\hline $28-36$ & Genel alıştırma & $\begin{array}{l}35 \text { numaralı solfejin varyasyonu mevcut. } 35 \text { numaralı } \\
\text { solfej ilk önce } 8 \text { 'lik nota ve 8'lik sus şeklinde } \\
\text { bestelenmişken, ikinci varyasyonunda 8'lik sus 8'lik } \\
\text { nota şeklinde düzenlenmiştir. }\end{array}$ \\
\hline $37-38$ & Birinci oktav ve altı çalışmalar & \\
\hline $39-40$ & İkinci ve üçüncü oktav çalışmalar & $\begin{array}{l}\text { Tiz seslerdeki ek çizgili notaların tanınması amaçlı } \\
\text { çalışmalar }\end{array}$ \\
\hline $41-48$ & 5'li, 6'lı, 7'li ve 8'li aralıklar & \\
\hline $49-67$ & $\begin{array}{l}\text { Uzatma noktası, uzatma bağı, legato bağı ve çift } \\
\text { uzatma noktası }\end{array}$ & $\begin{array}{l}\text { Uzatma noktası ile yazılan bazı solfejlerin uzatma bağ } 1 \\
\text { ile yazıldığı varyasyonlar mevcuttur. } 61 \text { numaralı } \\
\text { solfejden itibaren noktalı 4'lük 8'lik ile noktalı 8'lik } \\
16 \text { 'lık tartımı ile ilgili çalışmalar mevcuttur. }\end{array}$ \\
\hline $68-74$ & Kromatik çalışmalar - diyez, bemol ve natürel & \\
\hline $75-123$ & $\begin{array}{l}\text { Tonalite (Majör ve doğal, armonik, melodik minör } \\
\text { tonlar) }\end{array}$ & $\begin{array}{l}\text { La minör, Sol majör, Mi minör, Fa majör, Re minör, } \\
\text { Re majör, Si minör, Si bemol majör, Sol minör, La } \\
\text { majör, Fa\# minör, Mi bemol majör ve Do minör tonlar }\end{array}$ \\
\hline $124-137$ & $2 / 2,3 / 2$ ve $4 / 2$ ölçü çalışmaları & \\
\hline $138-159$ & Bas sesler için çalışmalar (Fa anahtarı) & \\
\hline $160-161$ & Tema ve varyasyonlar & $\begin{array}{l}160 \text { numaralı solfejin } 8,161 \text { numaralı solfejin } 7 \text { farklı } \\
\text { varyasyonu mevcut }\end{array}$ \\
\hline $162-190$ & Genel alıştırma & \\
\hline
\end{tabular}

Kitaptaki ilk 161 solfejin ölçüler birimleri, aralıklar, farklı ses oktavlarında çalışmalar, tonalite, Fa anahtarı ve tema - varyasyon gibi konulara odaklandığı görülmüştür. Her konudaki solfejlerin bir önceki konudaki elde edilen kazanımı pekiştiren solfejlerden oluştuğu tespit edilmiştir. Son 29 solfej genel alıştırma özelliği taşımaktadır. Ayrıca bazı solfejlerin farklı varyasyonlarının olduğu görülmüştür. Örneğin 3/4'lük ölçüde yazılmış olan bir solfejin ilerleyen sayfalarda 3/8'lik varyasyonu mevcuttur.

\section{Albert Lavignac, Henry Lemoine, Aldope Danhauser "Solfége des Solféges 1A ve 1B" Solfej Kitabı.}

Adolpe Danhause ve Henry Lemoine tarafindan yazılan ve çeşitli eserlerden derlenen, Albert Lavignac tarafından sınıflandırılması yapılan bu solfej kitabı ülkemizde mesleki müzik eğitimi veren kurumlar tarafindan oldukça yaygın bir kullanıma sahiptir. Hem farklı zorluk düzeylerinde hem farklı anahtar yapısında hem de farklı ses yapılarında toplam 34 solfej kitabından oluşmaktadır. Başlangıç düzeyinde 1A, 1B, 1C, 1D ve 1E olmak üzere 5 kitap bulunmaktadır. 1A, 1B kitaplarında hem Sol hem de Fa anahtarında solfejler bulunurken, 1C ve $1 \mathrm{D}$ kitaplarında Fa anahtarlı solfejler, 1E kitabında ise sadece sol anahtarlı solfejler bulunmaktadır. 1A ve 1B solfej kitapları başlangıç düzeyinde olduğu için ikisi tek başlık altında incelenmiştir.

Lavignac 1A solfej kitabının ilk 10 solfeji egzersiz niteliğinde olmak üzere toplam 204 solfejin olduğu görülmüş ve kitaptaki solfejler tablo 6'da açıklamaları ile gösterilmiştir. 
Tablo 6. “Lavignac 1A” solfej kitabının odaklandı̆̆ı konular ve açıklamaları

\begin{tabular}{|c|c|c|}
\hline $\begin{array}{c}\text { Solfej } \\
\text { Numarası }\end{array}$ & Odaklandığı konu ve konular & Açıklama \\
\hline $\mathrm{I}-\mathrm{IX}$ & Notalar ve entonasyon & \\
\hline $1-2$ & Do majör dizisi & \\
\hline $3-9$ & Aralıklar & 2'li, 3'lü, 4'lü, 5'li, 6'lı, 7'li ve 8'li aralıklar \\
\hline 10 & Genel alıştırma & \\
\hline $11-17$ & 4/4 ölçü çalışması, 1'lik, 2'lik nota ve sus değerleri & \\
\hline $18-21$ & Genel alıştırma & \\
\hline $22-30$ & 4'lük nota ve sus değerleri & \\
\hline 31 & Röpriz & \\
\hline 32 & Genel alıştırma & 4'lük nota ve sus değerleri ile Röpriz \\
\hline 33 & Senyö & \\
\hline $34-36$ & Genel alıştırma & $\begin{array}{l}\text { 1'lik 2'lik ve 4'lük nota ve sus değerleri ile } \\
\text { Röpriz }\end{array}$ \\
\hline $37-39$ & 8'lik nota ve sus değerleri & \\
\hline $40-43$ & Genel alıştırma & \\
\hline $44-61$ & 3/4, 2/2, 2/4 ölçü çalışması & \\
\hline $62-66$ & Uzatma noktası - legato bağ1 & \\
\hline 67 & Genel alıştırma & 4'lük, 8'lik, 16'lık notalar ve senyö \\
\hline $68-70$ & Uzatma noktası - legato bağ & \\
\hline $71-75$ & 3/8, 6/8 ölçü çalışması & \\
\hline $76-78$ & Üçleme & 8'lik ve 16'lik üçleme \\
\hline $79-83$ & Senkop & \\
\hline $84-88$ & Diyez (Kromatik çalışmalar) & \\
\hline $89-93$ & Genel alıştırma & \\
\hline $94-97$ & Bemol (Kromatik çalışmalar) & \\
\hline 98 & Genel alıştırma & \\
\hline $100-146$ & Tonalite & $\begin{array}{l}\text { La minör, Sol majör, Mi minör, Fa majör, } \\
\text { Re minör, Re majör, Si minör, Si bemol } \\
\text { majör, Sol minör }\end{array}$ \\
\hline $147-171$ & Fa anahtarı çalışmaları & \\
\hline $172-195$ & Genel alıştırma & $\begin{array}{l}\text { Notalar ve entonasyon, uzatma noktası ve } \\
\text { uzatma bağı, üçleme, senkop, } 6 / 8 \text { ölçüler, } \\
\text { Tonalite, Fa anahtarı }\end{array}$ \\
\hline
\end{tabular}

Lavignac 1A kitabında ilk 9 solfejin notalar ve entonasyon konusuna odaklandığ 1 ve içerik olarak diğer solfejlerden bağımsız numaralandırıldığı ve bu konuda yer alan solfejlerin Do majör tonunda yazıldığı tespit edilmiş̧tir. Tonalite konusuna kadar sırasıyla aralıklar, nota ve sus değerleri, tekrar işaretleri, uzatma noktası ve $2 / 4,3 / 4,2 / 2,3 / 8,6 / 8$ ölçü birimleri, üçleme ve senkop, diyez ve bemol konularına yönelik solfejlerin olduğu ve bu konularda yazılmış olan solfejlerin Do majör tonunda olduğu ve 4/4'lük ölçü biriminde olduğu görülmüş̧ür. Diyez ve bemoller konusuna yönelik solfejlerin kromatik alıştırmalar niteliği taşıyan solfejler olduğu, tonalite konusuna hazırlık özelliği taşıdığı ve sonrasında tonalite konusunun işlendiği görülmüştür. Tonalite konusunda yer alan solfejlerin sırasıyla La minör, Sol majör, Mi minör, Fa majör, Re minör, Re majör, Si minör, Sib majör, Sol minör tonlarında olduğu ayrıca bu solfejlerin kitapta yer alan önceki konuları pekiştiren genel alıştırma niteliği taşıdığı tespit edilmiştir. Kitapta Fa anahtarında solfej çalışmalarının olduğu, son 23 solfejin genel alıştırma özelliği taşıdığı görülmüştür.

Lavignac 1B solfej kitabında ilk 2'si egzersiz niteliğinde olmak üzere toplam 168 solfejin olduğu görülmüştür. Kitapta yer alan solfejlerin odaklandığı konular açıklamaları ile birlikte tablo 7'de gösterilmiştir. 
Tablo 7. “Lavignac 1B” solfej kitabının odaklandığı konular ve açıklamaları

\begin{tabular}{|c|c|c|}
\hline $\begin{array}{c}\text { Solfej } \\
\text { Numarası }\end{array}$ & Odaklandığı konu ve konular & Açıklama \\
\hline I - II & Notalar ve entonasyon & \\
\hline $1-10$ & 4/4 ölçü, 1'lik, 2'lik nota ve sus değerleri & \\
\hline $11-14$ & 4'lük nota ve sus değerleri & \\
\hline 15 & Senyö & \\
\hline $16-24$ & Genel alıştırma & 1'lik, 2'lik, 4'lük nota ve sus değerleri \\
\hline $25-26$ & 8'lik nota ve sus değerleri & \\
\hline $27-32$ & Genel alıştırma & Tüm nota ve sus değerleri \\
\hline $33-37$ & Uzatma noktası ve 3/4'lük ölçüler & 33 numaranın 2 farklı varyasyonu mevcut \\
\hline $38-42$ & 2/2 ölçü & \\
\hline $43-46$ & 2/4 ölçü & \\
\hline $47-52$ & Ölçü birimine göre uzatma noktası & \\
\hline $53-57$ & 16'lik notalar & \\
\hline $58-60$ & 3/8 ölçü & \\
\hline $61-64$ & 6/8 ölçü & \\
\hline $65-67$ & Üçleme & \\
\hline $68-73$ & Senkop & \\
\hline $74-80$ & Diyez & \\
\hline $81-85$ & Bemol & \\
\hline $86-89$ & Genel alıştırma & Diyez ve bemol \\
\hline $90-130$ & Tonalite & $\begin{array}{l}\text { La minör, Sol majör, Mi minör, Fa majör, Re } \\
\text { minör, Re majör, Si minör, Si bemol majör, } \\
\text { Sol minör, La majör, Fa\# minör, Mi bemol } \\
\text { majör ve Do minör tonlar }\end{array}$ \\
\hline $131-142$ & Fa anahtarı çalışmaları & \\
\hline $142-161$ & Genel alıştırma & Tonalite konusuna yönelik çalışmalar \\
\hline
\end{tabular}

Kitapta yer alan ilk 2 solfejin notalar ve entonasyon konusuna odaklandığı ve bu solfejlerin Do majör tonunda yazıldığı ve 4/4'lük ölçü biriminde olduğu tespit edilmiştir. Tonalite konusuna kadar sırasıyla aralıklar, nota ve sus değerleri, tekrar işaretleri, uzatma noktası ve 2/4, 3/4, 2/2, 3/8, 6/8 ölçü birimleri, üçleme ve senkop, diyez ve bemol konularına yönelik solfejlerin olduğu ve bu konularda yazılmış olan solfejlerin Do majör tonunda olduğu ve 4/4'lük ölçü biriminde yazıldığı görülmüştür. Bu bağlamda 1A kitabı ile benzer özellikler taşıdığı tespit edilmiştir. Tıpkı 1A kitabında olduğu gibi diyez ve bemollere yönelik alıştırmaların kromatik alıştırma özelliği taşıdığı ve tonalite konusuna hazırlayıcı özelliği sahip olduğu tespit edilmiştir. Tonalite konusunda sırasıyla La minör, Sol majör, Mi minör, Fa majör, Re minör, Re majör, Si minör, Sib majör, Sol minör, La majör, Fa\# minör, Mi bemol majör ve Do minör tonlarında solfejler olduğu görülürken, kitabında sonlarında $\mathrm{Fa}$ anahtarına yönelik solfejlerin olduğu ve son 19 solfejin tonalite konusuna yönelik genel alıştırmalar olduğu tespit edilmiştir.

\section{İkinci Alt Probleme Yönelik Bulgular ve Yorumlar}

"Solfej kitaplarında yer alan solfejler ölçü birimi yönünden nasıldır?" alt problemine yönelik bulgular ve yorumları tablo 8'de gösterilmiş ve yorumlanmıştır. 
Tablo 8. Solfejlerin ölçü birimlerine göre dă̆llımı

\begin{tabular}{|c|c|c|c|c|c|c|c|c|c|c|c|c|c|c|c|c|}
\hline \multirow{3}{*}{ 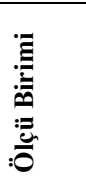 } & \multicolumn{2}{|c|}{$\begin{array}{l}\text { Petit } \\
\text { Solfege }\end{array}$} & \multicolumn{2}{|c|}{$\begin{array}{l}\text { Solfege } \\
\text { Elément. }\end{array}$} & \multicolumn{6}{|c|}{$\begin{array}{c}\text { Elementary Solfeggi for Medium Voice } \\
\text { Op } 9 \\
\end{array}$} & \multicolumn{2}{|c|}{$\begin{array}{l}\text { Corso Facile } \\
\text { di Solfege }\end{array}$} & \multicolumn{2}{|c|}{ Lavignac 1A } & \multicolumn{2}{|c|}{ Lavignac 1B } \\
\hline & & & & & \multicolumn{2}{|c|}{ Book 1} & \multicolumn{2}{|r|}{ Book 2} & \multicolumn{2}{|r|}{ Book3 } & & & & & & \\
\hline & f & $\%$ & f & $\%$ & f & $\%$ & $\mathbf{f}$ & $\%$ & $\mathbf{f}$ & $\%$ & f & $\%$ & f & $\%$ & f & $\%$ \\
\hline $2 / 4$ & 8 & 8 & 20 & 18,2 & 4 & 8 & 3 & 10 & 1 & 5,9 & 50 & 26,3 & 20 & 9,8 & 25 & 14,9 \\
\hline $3 / 4$ & 17 & 17 & 21 & 19,1 & 7 & 14 & 3 & 10 & 4 & 23,5 & 66 & 34,7 & 28 & 13,7 & 27 & 16,1 \\
\hline $4 / 4$ & 50 & 50 & 48 & 43,6 & 29 & 58 & 20 & 66,7 & 7 & 41,2 & 57 & 30 & 117 & 57,4 & 76 & 45,2 \\
\hline $3 / 8$ & 2 & 2 & 4 & 3,6 & 3 & 6 & 1 & 3,3 & 2 & 11,8 & 4 & 2,1 & 8 & 3,9 & 7 & 4,2 \\
\hline $6 / 8$ & 7 & 7 & 5 & 4,5 & 2 & 4 & 2 & 6,7 & 2 & 11,8 & - & - & 12 & 5,9 & 12 & 7,1 \\
\hline $9 / 8$ & 4 & 4 & 4 & 3,6 & 1 & 2 & - & - & 1 & 5,9 & - & - & - & - & - & - \\
\hline $2 / 2$ & 7 & 7 & 2 & 1,8 & 2 & 4 & 1 & 3,3 & - & - & 4 & 2,1 & 19 & 9,3 & 21 & 12,5 \\
\hline $6 / 4$ & 2 & 2 & - & - & - & - & - & - & - & - & - & - & - & - & - & - \\
\hline $12 / 8$ & 2 & 2 & 4 & 3,6 & 2 & 4 & - & - & - & - & - & - & - & - & - & - \\
\hline $3 / 2$ & 1 & 1 & 1 & 0,9 & - & - & - & - & - & - & 4 & 2,1 & - & - & - & - \\
\hline $4 / 2$ & - & - & 1 & 0,9 & - & - & - & - & - & - & 2 & 1,1 & - & - & - & - \\
\hline $2 / 8$ & - & - & - & - & - & - & - & - & - & - & 1 & 0,5 & - & - & - & - \\
\hline $4 / 8$ & - & - & - & - & - & - & - & - & - & - & 2 & 1,1 & - & - & - & - \\
\hline T. & 100 & 100 & 110 & 100 & 50 & 100 & 30 & 100 & 17 & 100 & 190 & 100 & 204 & 100 & 168 & 100 \\
\hline
\end{tabular}

"Petit Solfege" kitabında 2/4, 3/4, 4/4, 3/8, 6/8, 9/8, 2/2, 6/4, 12/8 ve 3/2 ölçü birimlerinde yazılmış olan solfejlerin olduğu tespit edilmiştir. Kitapta yer alan solfejlerin \%50'sinin ( $f=50)$ 4/4'lük ölçü biriminde yazıldığı, \%17'sinin (f=17) 3/4'lük ölçü biriminde yazıldığı görülürken, \%8'inin ( $f=8$ ) 2/4'lük ölçü biriminde yazılmış solfejlerin olduğu görülmektedir. Ayrıca kitapta bulunan solfejlerin \%2'sinin ( $\mathrm{f}=2$ ) $3 / 8^{\prime}$ lik ölçü biriminde, \%7'sinin (f=7) 6/8' lik ölçü biriminde, \%4'ünün (f=4) 9/8'lik ölçü biriminde, \%7'sinin (f=7) 2/2'lik ölçü biriminde, \%2'sinin (f=2) 12/8'lik ölçü biriminde ve \%1'inin (f=1) 3/2'lik ölçü biriminde yazıllmış olduğu görülmüştür.

"Solfege Elementary" solfej kitabında 2/4, 3/4, 4/4, 3/8, 6/8, 9/8, 2/2, 12/8, 3/2 ve 4/2 ölçü birimlerinde yazılmış olan solfejlerin olduğu görülmüştür. Solfejlerin \%43,6'sının (f=48) 4/4'lük ölçü biriminde, \%19,1'inin ( $\mathrm{f}=21$ ) 3/4'lük ölçü biriminde, \%18,2'sinin ise ( $\mathrm{f}=20$ ) 2/4'lük ölçü biriminde yazılmış olduğu görülmektedir. Kalan \%18,9'unun; \%3,6'sının (f=4) 3/8'lik, 9/8'lik ve 12/'lik ölçü birimlerindeki solfejlerden oluştuğu görülürken, \%4,5'inin (f=5) 6/8'lik ölçü biriminde yazılan solfejlerden oluştuğu görülmüştür. \%1,8'inin (f=2) 2/2'lik ve \%0,9'unun (f=1) 3/2'lik ve 4/2'lik ölçü birimlerinde yazılmış olan solfejlerden oluştuğu görülmüştür.

“Elementary Solfeggi for Medium Voice Op 9" solfej kitaplarının her üç kitabında 2/4, 3/4, 4/4, 3/8, 6/8 ölçü birimlerinde yazılmış solfejler bulunurken, birinci ve üçüncü kitaplarda ek olarak $9 / 8$, birinci ve ikinci kitaplarda $2 / 2$ ve sadece birinci kitapta 12/8'lik ölçü birimlerinde yazılmış solfejlerin olduğu tespit edilmiştir. Birinci kitapta yer alan solfejlerin \%58'inin ( $\mathrm{f}=29$ ) 4/4'lük ölçü biriminde, \%14'ünün ( $\mathrm{f}=7$ ) 3/4'lük ölçü biriminde, \%8'inin ise (f=4) 2/4'lük ölçü biriminde yazılmış olduğu görülmüştür. Solfejlerin \%6'sının ( $\mathrm{f}=3$ ) 3/8'lik ölçü biriminde, \%2'sinin (f=1) ise 9/8'lik ölçü biriminde yazılmış olduğu görülürken, \%4'ünün (f=2) 6/8, 2/2, 12/8'lik ölçü birimlerinde yazılmış olan solfejlerin olduğu tespit edilmiştir. İkinci kitapta yer alan solfejlerin \%66,7'sinin ( $\mathrm{f}=20)$ 
4/4'lük ölçü biriminde yazılmış olduğu, \%10'unun (f=3) ise 3/4'lük ve 2/4'lük ölçü birimlerinde yazılmış olduğu görülmektedir. Ayrıca kitaptaki solfejlerin \%6,7'sinin ( $\mathrm{f}=2$ ) 6/8'lik ölçü biriminde yazılmış olan solfejlerden oluştuğu görülürken, \%3,3'ünün (f=1) 3/8'lik ve 2/2'lik ölçü birimlerinde olduğu görülmüştür. Üçünü kitapta yer alan solfejler ölçü birimi noktasında diğer iki kitaba göre daha dar bir yelpazede kaldıkları tespit edilmiştir. Kitapta yer alan solfejlerin \%41,2'si (f=7) 4/4'lük ölçü biriminde, \%23,5'i (f=4) 3/4'lük ölçü biriminde, \%5,9'unun (f=1) ise 2/4'lük ölçü biriminde olduğu görülmektedir. Solfejlerin \%11,8'inin (f=2) 3/8 ve 6/8'lik ölçü birimlerinde olduğu, \%5,9'unun ( $\mathrm{f}=1$ ) ise 9/8'lik ölçü biriminde olduğu görülmüştür.

"Corso Facide di Sofege" solfej kitabında 2/4, 3/4, 4/4, 3/8, 2/2, 3/2, 4/2, 2/8, 4/8 ölçü birimlerinde yazılmış olan solfejlerin bulunduğu görülmüştür. Solfejlerin \%34,7'sinin ( $\mathrm{f}=66$ ) 3/4'lük ölçü biriminde, \%30'nunu ( $\mathrm{f}=57$ ) 4/4'lük ölçü biriminde, \%26,3'ünün ( $\mathrm{f}=50$ ) 2/4'lük ölçü biriminde olduğu görülmektedir. Kitaptaki solfejlerin $\% 2,1$ 'inin (f=4) 3/8, 2/2 ve 3/2 ölçü birimlerinde olduğu, $\% 1,1$ 'inin (f=2) 4/2 ve $4 / 8$ ölçü birimlerinde olduğu görülürken, \%0,5'inin ( $\mathrm{f}=1$ ) 2/8'lik ölçü biriminde olduğu tespit edilmiştir.

Lavignac 1A ve 1B kitaplarında 2/4, 3/4, 4/4, 3/8, 6/8, 2/2 ölçü birimlerinde yazılmış solfejlerin olduğu tespit edilmiştir. Lavignac 1A solfej kitabında yer alan solfejlerin \%57,4'ünün (f=117) 4/4 ölçü biriminde, \%13,7'sinin ( $\mathrm{f}=28$ ) 3/4'lük ölçü biriminde, $\% 9,8$ 'ini ( $\mathrm{f}=20$ ) 2/4'lük ölçü biriminde olduğu görülmüştür. Kitaptaki solfejlerin \%9,3'ünün (f=19) 2/2 ölçü biriminde, \%5,9'unun ( $\mathrm{f}=12$ ) 6/8'lik ölçü biriminde ve \%3,9'unun ( $\mathrm{f}=8$ ) 3/8'lik ölçü biriminde olduğu tespit edilmiştir.

Lavignac 1B kitabındaki solfejlerin \%45,2'sinin (f=76) 4/4'lük ölçü biriminde, \%16,1'inin (f=27) 3/4'lük ölçü biriminde, \%16,9'unun (f=25) 2/4'lük ölçü biriminde olduğu görülürken; \%12,5'inin ( $\mathrm{f}=21$ ) 2/2'lik ölçü biriminde, \%7,1'inin ( $\mathrm{f}=12$ ) 9/8' lik ölçü biriminde, \%4,2 sinin ( $\mathrm{f}=7$ ) 3/8'lik ölçü biriminde olduğu görülmüştür.

\section{Üçüncü Alt Probleme Yönelik Bulgular ve Yorumlar}

"Solfej kitaplarında yer alan solfejlerin ton yönünden oluşumu nasıldır?" alt problemine yönelik bulgular ve yorumları tablo 9' da ifade edilmiştir. 
Tablo 9. Solfejlerin tonlarına göre dağılımı

\begin{tabular}{|c|c|c|c|c|c|c|c|c|c|c|c|c|c|c|c|c|}
\hline \multirow[t]{3}{*}{ Ton } & \multirow{2}{*}{\multicolumn{2}{|c|}{$\begin{array}{c}\text { Petit } \\
\text { Solfege }\end{array}$}} & \multirow{2}{*}{\multicolumn{2}{|c|}{$\begin{array}{c}\text { Solfege } \\
\text { Elément. }\end{array}$}} & \multicolumn{6}{|c|}{$\begin{array}{c}\text { Elementary Solfeggi for Medium Voice } \\
\text { Op } 9 \\
\end{array}$} & \multirow{2}{*}{\multicolumn{2}{|c|}{$\begin{array}{l}\text { Corso Facile } \\
\text { di Solfege }\end{array}$}} & \multirow{2}{*}{\multicolumn{2}{|c|}{ Lavignac 1A }} & \multirow{2}{*}{\multicolumn{2}{|c|}{ Lavignac 1B }} \\
\hline & & & & & \multicolumn{2}{|c|}{ Book 1} & \multicolumn{2}{|c|}{ Book 2} & \multicolumn{2}{|c|}{ Book3 } & & & & & & \\
\hline & f & $\%$ & f & $\%$ & f & $\%$ & $\mathbf{f}$ & $\%$ & $\mathbf{f}$ & $\%$ & $\mathbf{f}$ & $\%$ & f & $\%$ & $\mathbf{f}$ & $\%$ \\
\hline $\begin{array}{c}\text { Do } \\
\text { Majör }\end{array}$ & 45 & 45 & 44 & 40 & 29 & 58 & 14 & 46,7 & 2 & 11,8 & 92 & 48,4 & 130 & 63,7 & 102 & 60,7 \\
\hline $\begin{array}{c}\text { La } \\
\text { Minör }\end{array}$ & 18 & 18 & 6 & 5,5 & 4 & 8 & 1 & 3,3 & - & - & 11 & 5,8 & 10 & 4,9 & 6 & 3,6 \\
\hline $\begin{array}{c}\text { Fa } \\
\text { Majörr }\end{array}$ & 3 & 3 & 8 & 7,3 & 5 & 10 & 4 & 13,3 & 2 & 11,8 & 14 & 7,4 & 11 & 5,4 & 14 & 8,3 \\
\hline $\begin{array}{c}\operatorname{Re} \\
\text { Minör }\end{array}$ & 2 & 2 & 5 & 4,5 & 2 & 4 & - & - & - & - & 4 & 2,1 & 9 & 4,4 & 6 & 3,6 \\
\hline $\begin{array}{c}\text { Sol } \\
\text { Majör }\end{array}$ & 4 & 4 & 11 & 10 & 3 & 6 & 3 & 10 & 2 & 11,8 & 9 & 4,7 & 14 & 6,9 & 12 & 7,1 \\
\hline $\begin{array}{c}\text { Mi } \\
\text { Minör }\end{array}$ & 3 & 3 & 4 & 3,6 & 2 & 4 & 1 & 3,3 & - & - & 6 & 3,2 & 8 & 3,9 & 7 & 4,2 \\
\hline $\begin{array}{c}\text { Si b } \\
\text { Majörr }\end{array}$ & 4 & 4 & - & - & 2 & 4 & 2 & 6,7 & 1 & 5,9 & 6 & 3,2 & 7 & 3,4 & 5 & 3 \\
\hline $\begin{array}{c}\text { Sol } \\
\text { Minör }\end{array}$ & 1 & 1 & - & - & - & - & - & & 1 & 5,9 & 8 & 4,2 & 4 & 2 & 6 & 3,6 \\
\hline $\begin{array}{c}\operatorname{Re} \\
\text { Majör }\end{array}$ & 4 & 4 & - & - & - & - & 4 & 13,3 & 2 & 11,8 & 11 & 5,8 & 7 & 3,4 & 7 & 4,2 \\
\hline Si Minör & 1 & 1 & - & - & - & - & - & - & - & - & - & - & 4 & 2 & 3 & 1,8 \\
\hline $\begin{array}{l}\text { Mi b } \\
\text { Majör }\end{array}$ & 1 & 1 & 5 & 4,5 & 1 & 2 & - & - & 3 & 17,6 & 7 & 3,7 & - & - & - & - \\
\hline $\begin{array}{c}\text { Do } \\
\text { Minör }\end{array}$ & 1 & 1 & 2 & 1,8 & 1 & 2 & 1 & 3,3 & 1 & 5,9 & 5 & 2,6 & - & - & - & - \\
\hline $\begin{array}{c}\text { La } \\
\text { Majörr }\end{array}$ & 1 & 1 & 5 & 4,5 & - & - & - & - & - & - & 6 & 3,2 & - & - & - & - \\
\hline $\begin{array}{c}\text { Fa\# } \\
\text { Minör }\end{array}$ & 1 & 1 & 3 & 2,7 & - & - & - & - & - & - & - & - & - & - & - & - \\
\hline $\begin{array}{c}\text { La b } \\
\text { Majör }\end{array}$ & 1 & 1 & - & - & - & - & - & - & 1 & 5,9 & - & - & - & - & - & - \\
\hline $\begin{array}{c}\text { Fa } \\
\text { Minör }\end{array}$ & 1 & 1 & - & - & - & - & - & - & - & - & - & - & - & - & - & - \\
\hline $\begin{array}{c}\text { Mi } \\
\text { Majörr }\end{array}$ & 2 & 2 & - & - & - & - & - & - & - & - & - & - & - & - & - & - \\
\hline $\begin{array}{c}\text { Do\# } \\
\text { Minör }\end{array}$ & - & - & - & - & - & - & - & - & 1 & 5,9 & - & - & - & - & - & - \\
\hline $\begin{array}{c}\operatorname{Re} b \\
\text { Majör }\end{array}$ & - & - & - & - & - & - & - & - & 1 & 5,9 & - & - & - & - & - & - \\
\hline Si Majör & 1 & 1 & 4 & 3,6 & - & - & - & - & & & 6 & 3,2 & - & - & - & - \\
\hline $\begin{array}{c}\text { Sol b } \\
\text { Majör }\end{array}$ & 1 & 1 & 5 & 4,5 & - & - & - & - & - & - & - & - & - & - & - & - \\
\hline $\begin{array}{c}\text { Fa\# } \\
\text { Majör }\end{array}$ & - & - & - & - & - & - & - & - & - & - & 5 & 2,6 & - & - & - & - \\
\hline $\begin{array}{c}\text { Do b } \\
\text { Majör }\end{array}$ & 1 & 1 & - & - & - & - & - & - & - & - & - & - & - & - & - & - \\
\hline $\begin{array}{c}\text { Majör } \\
\text { Dizi }\end{array}$ & 2 & 2 & - & - & - & - & - & - & - & - & - & - & - & - & - & - \\
\hline $\begin{array}{l}\text { Minör } \\
\text { Dizi }\end{array}$ & 2 & 2 & - & - & - & - & - & - & - & - & - & - & - & - & - & - \\
\hline Top. & 100 & 100 & 110 & 100 & $\mathbf{5 0}$ & 100 & 30 & 100 & 17 & 100 & 190 & 100 & 204 & 100 & 168 & 100 \\
\hline
\end{tabular}

"Petit Solfege" kitabının 20 farklı tonda yazılmış toplam 100 solfej olduğu görülmektedir. Ayrıca kitapta Sol ve Fa anahtarlarında yazılmış tüm tonlara yönelik majör - minör dizi çalışmalarının olduğu tespit edilmiştir. Kitapta bulunan solfejlerin \%45’i (f=45) Do majör tonunda, \%18’i (f=18) La minör tonunda, \%4’ü (f=4) Sol majör, Sib majör, Re majör tonlarında yazıldığı görülmüştür. Ayrıca solfejlerin \%3’ünü (f=3) Fa majör ve Mi minör tonlarındaki solfejler oluştururken, Mi majör ve Re minör tonlarındaki solfejler kitaptaki solfejlerin \%2'sini (f=2) 
oluşturmaktadır. Kitaptaki solfejlerin \%1'ini (f=1) Sol minör, Si minör, Mib majör, Do minör, La majör, Fa\# minör, Lab majör, Fa minör, Si majör, Sol bmajör, Dob majör tonlarındaki solfejlerin oluşturduğu görülmüştür.

"Solfege Elementary" kitabında 110 solfejin olduğu ve bu solfejlerin 12 farklı tonda yazıldığı tespit edilmiştir. Kitaptaki solfejlerin \%40'1nın ( $\mathrm{f}=44$ ) Do majör tonunda, \%10'unun ( $\mathrm{f}=11$ ) Sol majör tonunda, \%7,3’ünün ( $\mathrm{f}=8$ ) Fa majör tonunda, \%5,5'inin ( $\mathrm{f}=6$ ) La minör tonunda olduğu görülmüştür. Ayrıca solfejlerin \%4,5'inin ( $\mathrm{f}=5) \mathrm{Re}$ minör, Mib majör, Solb majör ve La majör tonlarında oldukları görülürken, \%3,6'sının (f=4) Si majör ve Mi minör tonlarında olduğu, \%2,7'sinin ( $f=3)$ Fa\# minör tonunda ve \%1,8'inin ( $f=2)$ Do minör tonunda olduğu tespit edilmiştir.

"Elementary Solfeggi for Medium Voice Op 9" solfej kitaplarında; birinci kitapta yer alan 50 solfejin 9 farklı tonda, ikinci kitaptaki yer alan 30 solfejin 8 farklı tonda ve üçüncü kitapta yer alan 17 solfejin 11 farklı tonda yazıldığı tespit edilmiştir. Birinci kitaptaki solfejlerin \%58'inin ( $f=29)$ Do majör tonunda, \%10'unun ( $f=5$ ) fa majör tonunda, \%8'inin ( $\mathrm{f}=4$ ) La minör tonunda, $\% 6$ 'sının ( $\mathrm{f}=3$ ) sol minör tonunda yazıldığı görülmüștür. Ayrıca solfejlerin \%4'ünün ( $\mathrm{f}=2$ ) Re minör, Mi minör ve Sib majör tonlarında olduğu görülürken, \%2'sinin ( $\mathrm{f}=1$ ) Mib majör ve Do minör tonlarında olduğu tespit edilmiştir. İkinci kitapta yer alan solfejlerin \%46,7'sinin (f=14) Do majör tonunda, \%13,3’ünün ( $\mathrm{f}=4$ ) Fa majör ve Re majör tonlarında, \%10'unun (f=3) Sol majör tonunda olduğu görülürken, \%6,7'sinin ( $\mathrm{f}=2$ ) Sib majör tonunda, \%3,3’ünün ( $\mathrm{f}=1$ ) La minör, Mi minör ve Do minör tonlarında olduğu görülmüştür. Üçüncü kitaptaki solfejlerin \%17,6'sının ( $\mathrm{f}=3$ ) Mib majör tonunda, \%11,8'inin ( $\mathrm{f}=2$ ) Do majör, Fa majör, Sol Majör ve Re majör tonlarında olduğu görülürken, \%5,9’unun ( $\mathrm{f}=1$ ) Sib majör, Sol minör, Do\# minör, Reb majör, Lab majör, Lab majör ve Do minör tonlarında olduğu görülmüştür.

"Corso Facide di Sofege" solfej kitabında 190 tane solfejin olduğu görülürken bu solfejlerin 14 farklı tonda yazıldığı tespit edilmiştir. Kitaptaki solfejlerin \%48,4’ü ( $f=92)$ Do majör tonunda, \%7,4’ü ( $f=14)$ Fa minör tonunda, \%5,8’i ( $\mathrm{f}=11$ ) La minör tonunda, \%4,7'si ( $\mathrm{f}=9$ ) Sol majör tonunda, \%4,2'si ( $\mathrm{f}=8$ ) Sol minör tonunda ve \%3,7’si (f=7) Mib majör tonunda yazılmıştır. Ayrıca kitaptaki solfejlerin \%3,2'sinin (f=6) Mi minör, Si majör, Sib majör ve La majör tonlarında yazıldığı tespit edilirken, \%2,6'sının ( $f=5)$ Do minör ve Fa\#\# majör tonlarında, \%2,1'inin ise Re minör tonunda yazıldı̆̆

Lavignac 1A solfej kitabında 10 farklı tonda 204 solfejin olduğu tespit edilmiş̧ir. Kitapta bulunan solfejlerin \%63,7'si (f=130) Do majör tonunda, \%6,9'u (f=14) Sol majör tonunda, \%5,4’ü (f=11) Fa majör tonunda, \%4,9’u $(\mathrm{f}=10)$ La minör tonunda yazılmıştır. Solfejlerin \%4,4'ünün ( $\mathrm{f}=9$ ) Re minör ve $\% 3,9$ 'unun ( $\mathrm{f}=8$ ) Mi minör tonlarında yazıldığı görülürken, \%3,4'ünün ( $\mathrm{f}=7$ ) Sib majör ve Re majör tonlarında, \%2'sinin ise ( $\mathrm{f}=4$ ) Sol minör ve Si minör tonlarında yazılmış olduğu tespit edilmiştir.

Lavignac 1B kitabında ise 168 solfejin 10 farklı tonda yazılmış olduğu görülmüştür. Kitapta bulunan solfejlerin \%60,7'si ( $\mathrm{f}=102$ ) Do majör tonunda, \%8,3'ü ( $\mathrm{f}=14$ ) Fa majör tonunda, \%7,1'i ( $\mathrm{f}=12$ ) Sol majör tonunda yazılmıştır. Ayrıca kitaptaki solfejlerin \%4,2'sinin ( $\mathrm{f}=7$ ) Mi minör ve Re majör tonlarında olduğu, \%3,6'sının $(\mathrm{f}=6)$ La minör, Re minör ve Sol minör tonlarında olduğu, \%3'ünün ( $\mathrm{f}=5$ ) Sib majör tonunda olduğu görülürken $\% 1,8$ 'inin (f=3) Si minör tonunda olduğu görülmüştür. 


\section{Dördüncü Alt Probleme Yönelik Bulgular ve Yorumlar}

“Solfej kitaplarında yer alan solfejlerin anahtar yönünden oluşumu nasıldır?” alt problemine yönelik bulgular ve yorumları tablo 10' da ifade edilmiştir.

Tablo 9. Solfejlerin anahtar yönünden oluşumu

\begin{tabular}{|c|c|c|c|c|c|c|c|c|c|c|c|c|c|c|c|c|}
\hline \multirow{3}{*}{$\underset{\sum}{\stackrel{\Xi}{\Xi}}$} & \multicolumn{2}{|c|}{$\begin{array}{c}\text { Petit } \\
\text { Solfege }\end{array}$} & \multicolumn{2}{|c|}{$\begin{array}{c}\text { Solfege } \\
\text { Elément. }\end{array}$} & \multicolumn{6}{|c|}{$\begin{array}{c}\text { Elementary Solfeggi for Medium Voice } \\
\text { Op } 9 \\
\end{array}$} & \multicolumn{2}{|c|}{$\begin{array}{l}\text { Corso Facile } \\
\text { di Solfege }\end{array}$} & \multicolumn{2}{|c|}{ Lavignac 1A } & \multirow{2}{*}{\multicolumn{2}{|c|}{ Lavignac 1B }} \\
\hline & & & & & & ook 1 & & Book 2 & & Book3 & & & & & & \\
\hline & $\mathbf{f}$ & $\%$ & $\mathbf{f}$ & $\%$ & f & $\%$ & $\mathbf{f}$ & $\%$ & $\mathbf{f}$ & $\%$ & $\mathbf{f}$ & $\%$ & f & $\%$ & $\mathbf{f}$ & $\%$ \\
\hline Sol & 89 & 89 & 110 & 100 & 50 & 100 & 30 & 100 & 17 & 100 & 137 & 72,1 & 175 & 85,8 & 142 & 84,5 \\
\hline $\mathbf{F a}$ & 11 & 11 & - & - & - & - & - & - & - & - & 53 & 27,9 & 29 & 14,2 & 26 & 15,5 \\
\hline Top. & 100 & 100 & 110 & 100 & $\mathbf{5 0}$ & 100 & 30 & 100 & 17 & 100 & 190 & 100 & 204 & 100 & 168 & 100 \\
\hline
\end{tabular}

Solfej kitapları anahtar yönünden incelendiğinde; "Solfege Elémentary” kitabında ve "Elementary Solfeggi for Medium Voice op 9" kitaplarının üçünde de Fa anahtarlı solfejlerin olmadığı görülmüştür.

"Petit Solfege" kitabında yer alan solfejlerin \%89'unun ( $f=89$ ) Sol anahtarl, \%11'inin ( $f=11$ ) Fa anahtarlı solfejlerden oluştuğu; "Corso Facile di Solfege” kitabında yer alan solfejlerin \%72,1'inin (f=137) Sol anahtarlı, \%27,9'unun (f=53) Fa anahtarlı solfejlerden oluştuğu görülmüştür. "Lavignac 1A” solfej kitabında bulunan solfejlerin \%85,8'inin ( $\mathrm{f}=175$ ) Sol anahtarlı, \%14,2'sinin (f=29) Fa Anahtarlı solfejlerden oluştuğu görülürken; “Lavignac 1B" solfej kitabının \%84'5'inin (f=142) sol anahtarlı solfejlerden, \%15,5'inin (f=26) ise Fa anahtarlı solfejlerden oluştuğu tespit edilmiştir.

Genel anlamda başlangıç düzeyinde hazırlanan kitapların içerdiği, kazandırmaya veya pekiştirmeye çalıştığı konular noktasında, öğrencilerin farklı bir anahtarla uğraşmamaları ve tüm dikkatlerini solfejin kazandırmaya çalıştığı teorik konuya odaklayabilmesi nedeniyle kitaplarda bulunan solfejlerin Sol anahtarı ağırlıklı olduğu düşünülmektedir.

\section{Beşinci Alt Probleme Yönelik Bulgular ve Yorumlar}

“Solfej kitaplarında yer alan solfejlerin ses aralığı yönünden oluşumu nasıldır?" alt problemine yönelik bulgular elde edilirken, kitaplardaki Sol anahtarlı ve Fa anahtarlı solfejler oktav farkından dolayı ayrı ayrı incelenmiştir. Solfej kitaplarındaki ses aralığının çeşitliliğinden dolayı Fa ve Sol anahtarlı solfejlerde en yüksek orana sahip ilk 10 solfej grafikler üzerinden yorumlanmıştır.

"Petit solfege" kitabına yer alan Sol ve Fa anahtarındaki solfejlerin ses aralıkları Grafik 1'de gösterilmiş ve yorumlanmıştır. 
Grafik 1. "Petit Solfege" kitabinda bulunan Sol anahtarlt solfejlerin ses aralıklart

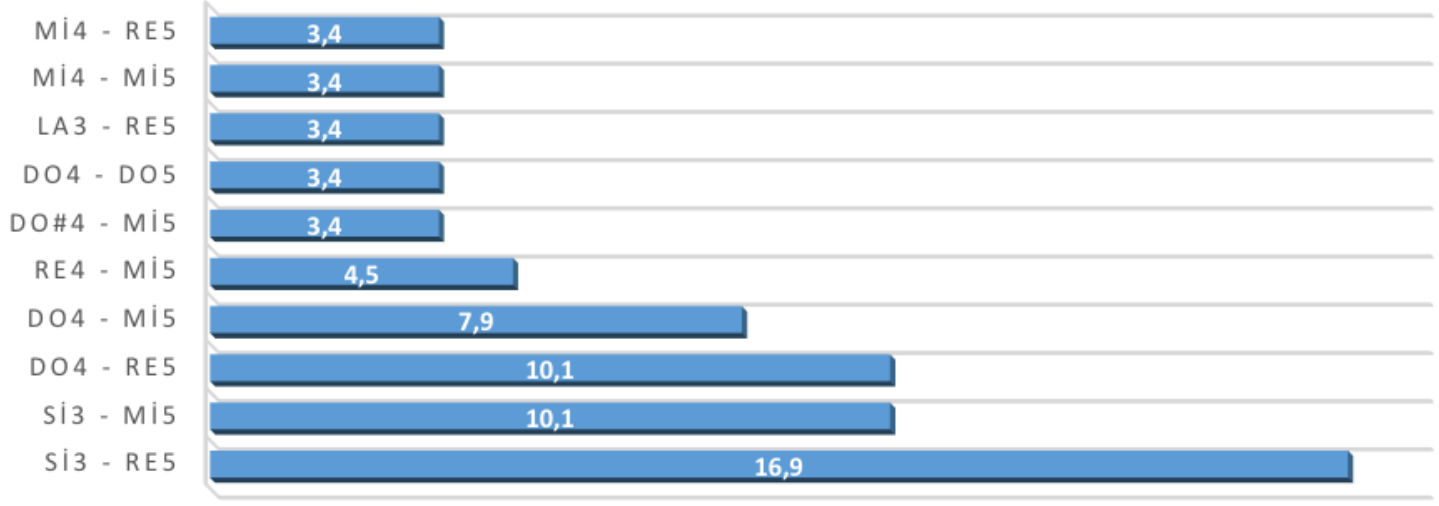

"Petit Solfege" kitabında 89'u Sol anahtarlı, 11'i Fa anahtarlı olmak üzere toplam 100 solfej bulunduğu görülürken, Sol anahtarlı solfejlerde 31, Fa anahtarlı solfejlerde ise 6 farklı ses aralığı olduğu görülmüştür.

Kitapta bulunan Sol anahtarlı 89 solfejin, en yüksek orana sahip ilk 10 solfejinin ses aralıkları incelendiğinde; Solfejlerin \%16,9'unun (f=15) Si3 - Re5 aralığında olduğu, \%10,1'erlik (f=9) kısımlarının Do4 - Re5 ve Si3 Mi5 ses aralıklarında olduğu görülmüştür. Solfejlerin \% 7,9’unun (f=7) Do4 - Mi5 aralığında olduğu, \%4,5'inin (f=4) ise Re4 - Mi5 aralığında olduğu tespit edilmiştir. \%3,4'erlik (f=3) oranların ise Mi4 - Re5, Mi4 - Mi5, La3 - Re5 ve Do4 - Do5 aralıklarında olduğu görülmüştür.

Kitapta bulunan Fa anahtarlı 11 solfej 6 farklı ses aralığından oluştuğu tespit edilmiştir. Yapılan analizlerde solfejlerden birinin Fa anahtarlarında tüm tonlarda dizi çalışması olduğu görülerek incelemeden çıkartılmış ve kalan solfejlerin ses aralıkları yönünden analizi Grafik 2’de gösterilmiştir.

Grafik 2. "Petit Solfege" kitabında bulunan Fa anahtarlt solfejlerin ses aralıklart

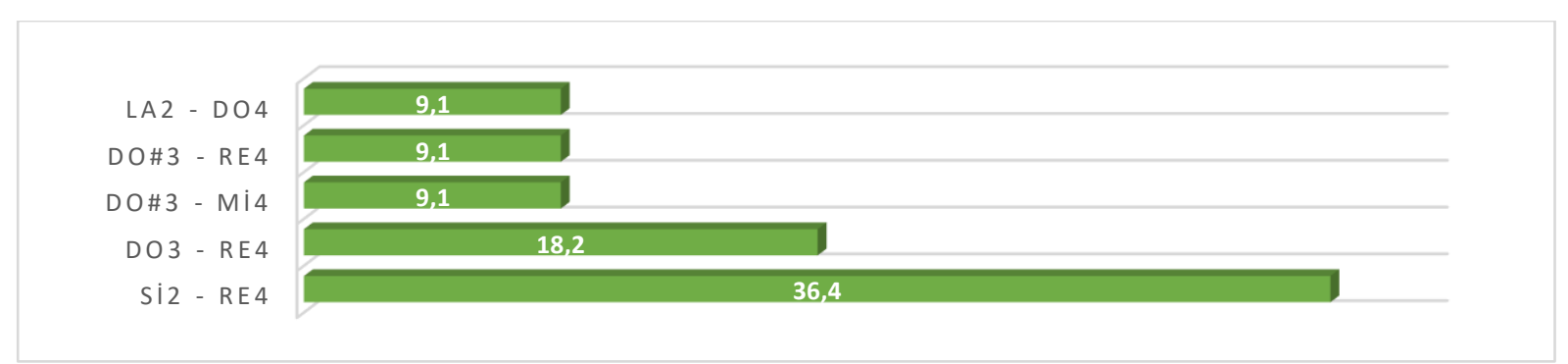

Kitapta bulunan Fa anahtarlı solfejlerin \%36,4'ünün (f=4) Si2 - Re4 aralığında olduğu, \%18,2'sinin (f=2) Do3 - Re4 aralığında olduğu görülürken, \%9,1'erlik ( $\mathrm{f}=1)$ oranların ise Do\#3 - Mi4, Do\#3 - Re4 ve La2 - Do4 aralığında olduğu görülmüştür.

"Solfege Elementary" kitabına sadece Sol anahtarlı 110 solfej olduğu ve 20 çeşit ses aralığı olduğu görülmüştür. Grafik 3'de kitapta bulunan en yüksek orana sahip 10 ses aralığı gösterilmiştir. 
Grafik 3. "Solfege Elementary" kitabında bulunan solfejlerin ses aralıklart
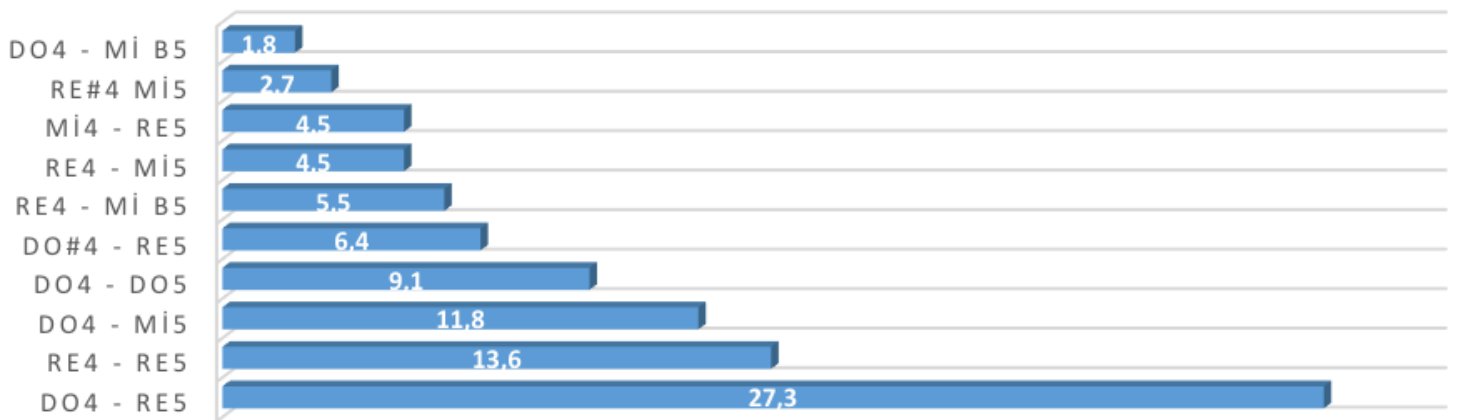

Kitapta bulunan solfejlerin \%27,3'ünün (f=30) Do4 - Re5 aralığında olduğu, \%13,6'sının (f=15) Re4 - Re5 aralığında olduğu, \%11,8'inin (f=13) Do4 - Mi5 aralığında olduğu görülmüştür. Solfejlerin \%9,1'inin (f=10) Do4 - Do5 aralığında olduğu, \%6,4'ünün ( $\mathrm{f}=7$ ) Do\#4 - Re5 aralığında olduğu, \%5,5'inin ( $\mathrm{f}=6$ ) ise Re4 - Mib5 aralığında olduğu tespit edilmiştir. Re4 - Mi5 ve Mi4 - Re5 aralığındaki solfejlerin oranının \%4,5 (F=5) olduğu görülürken, \%2,7’sinin (f=3) Re\#4 - Mi5 aralığında, \%1,8 (f=2) Do4 Mib5 aralığında olduğu tespit edilmiştir.

“Elementary Solfeggi for Medium Voice Op.9” birinci kitapta 50 solfejin ve 19 farklı ses aralığının olduğu görülmüştür. Serinin birinci kitabı olan bu kitapta yer alan en yüksek orana sahip ilk 10 solfejin ses aralıkları grafik 4’te gösterilmiştir.

Grafik 4. “Elementary Solfeggi for Medium Voice Op.9” birinci kitapta bulunan solfejlerin ses araltklart

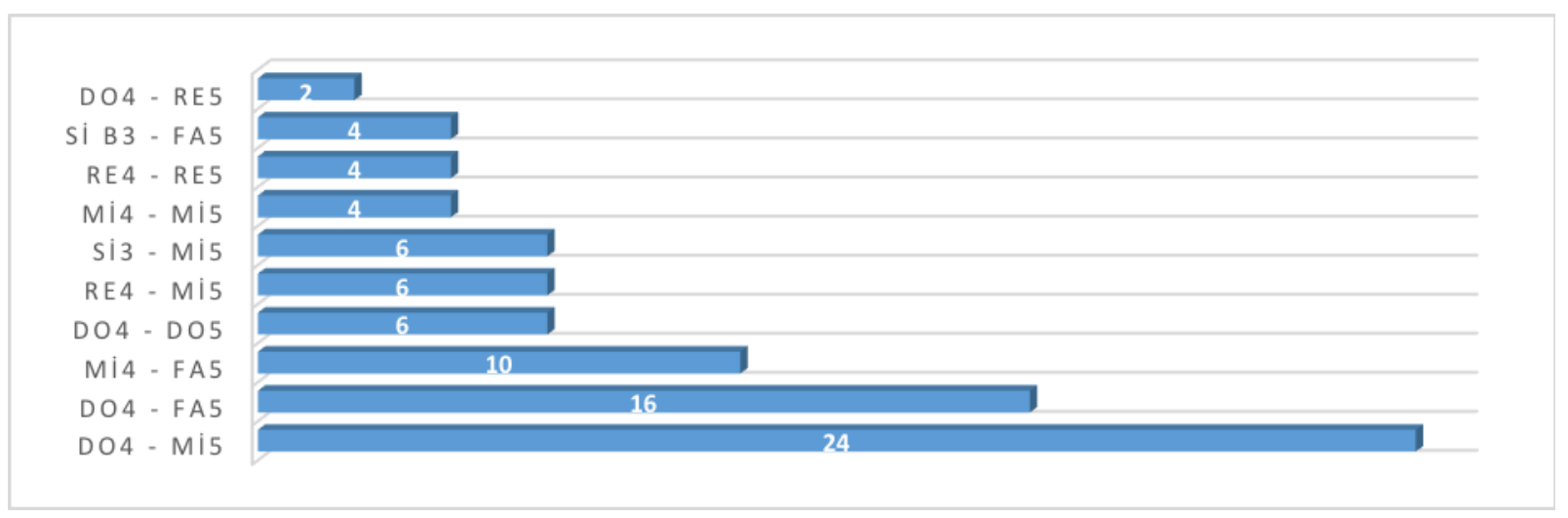

Kitapta bulunan solfejlerin \%24'ünün (f=12) Do4 - Mi5 aralığında olduğu, \%16'sının (f=8) Do4 - Fa5 aralığında olduğu, \%10’unun (f=5) Mi4 - Fa5 aralığında olduğu görülmektedir. Aynı zamanda Do4 - Do5, Re4 Mi5 ve Si3 - Mi5 ses aralığındaki solfejlerin \%6’lık (f=3) oranlarda yer aldığı görülürken, Mi4 - Mi5, Re4 - Re5 ve Sib3 - Fa5 ses aralığındaki solfejlerin ise \%4'lük (f=3) oranda yer aldığı görülmektedir. Solfejlerin \%2'sinin ise $\mathrm{Si} 3$ - Fa5 aralığında olduğu tespit edilmiştir.

“Elementary Solfeggi for Medium Voice Op.9” ikinci kitapta 30 solfejin ve 11 farklı ses aralığının olduğu görülmüştür. Kitapta yer alan ses aralıklarının çeşitliliği grafikleştirmek için belirlenen değere yakın bir değer olduğu için tüm ses aralıkları dâhil edilmiş ve grafik 5 'te gösterilmiştir. 
Grafik 5. "Elementary Solfeggi for Medium Voice Op.9” ikinci kitapta bulunan solfejlerin ses aralklart
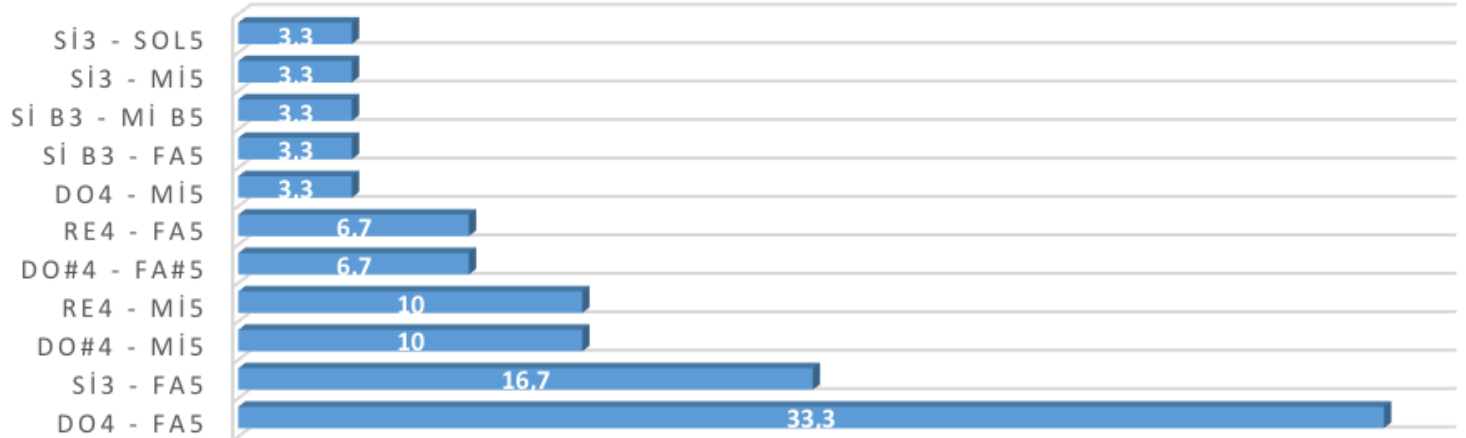

Solfejler incelendiğin; \%33,3'ünün (F=10) Do4 - Fa5 aralığında olduğu, \%16,7'sinin (5) Si3 - Fa5 aralığında olduğu tespit edilmiştir. Do\#4 - Mi5 ve Re4 - Mi5 aralığındaki solfejlerin \%10'arlık (f=3) oranlara ve Do\#4 Fa5 ve Re4 - Fa5 aralığındaki solfejlerin \%6,7'şerlik (f=2) oranlara sahip olduğu görülmüştür. Do4 - Mi5, Sib3 Fa5, Sib3 - Mib5, Si3 - Mi5 ve Si3 - Sol5 ses aralıklarına sahip solfejlerin \%3,3'erlik (f=1) oranlarda olduğu görülmüştür.

“Elementary Solfeggi for Medium Voice Op.9” üçüncü kitapta 17 solfejin ve 12 farklı ses aralığının olduğu görülmüştür. Kitapta yer alan ses aralıklarının çeşitliliği grafikleştirmek için belirlenen değere yakın bir değer olduğu görülmüş ve tüm ses aralıkları dâhil edilerek grafik 6'da gösterilmiştir.

Grafik 6. “Elementary Solfeggi for Medium Voice Op.9” üçüncü kitapta bulunan solfejlerin ses aralıkları
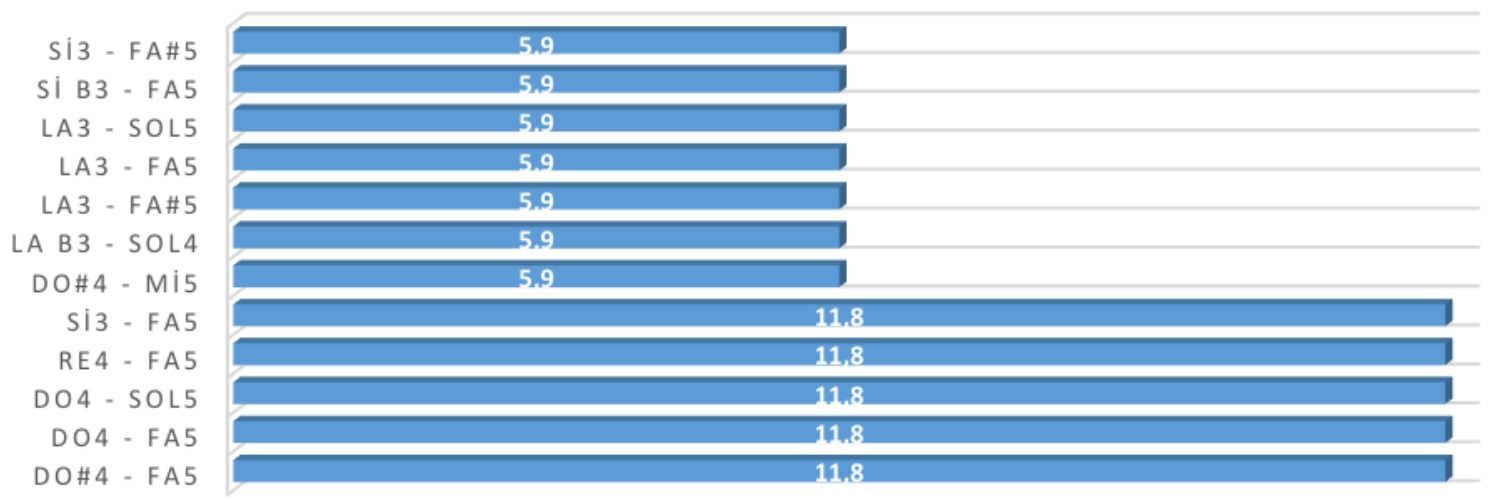

Kitapta yer alan solfejlerin ses aralıkları yönünden dengeli bir şekilde dağıldığı tespit edilmiştir. Do\#4 - Fa5, Do4 - Fa5, Do4 - Sol5, Re4 - Fa5 ve Si3 - Fa5 aralığındaki solfejlerin \%11,8'erlik (f=2) oranlara sahip olduğu görülmüştür. Benzer şekilde Do\#4 - Mi5, Lab3 - Sol4 - La3 - Fa\#5, La3 - Fa5, La3 - Sol5, Sib3 - Fa5 ve Si3 Fa\#5 aralığındaki solfejlerin \%5,9'arlık (f=1) oranlara sahip olduğu tespit edilmiştir.

Ettore Pozzoli tarafindan hazırlanan “Corso Facile Di Solfeggio” solfej kitabında 137'si Sol anahtarl1, 53'ü Fa anahtarlı olmak üzere toplam 190 solfejin olduğu görülmüştür. Sol anahtarlı solfejler incelendiğinde 137 solfejin 45 çeşit ses aralığında olduğu tespit edilmiştir. En yüksek orana sahip 10 ses aralığ 1 grafik 7'de gösterilmiştir. 
Grafik 7. “Corso Facile Di Solfeggio” kitabında bulunan Sol anahtarlt solfejlerin ses aralıklart

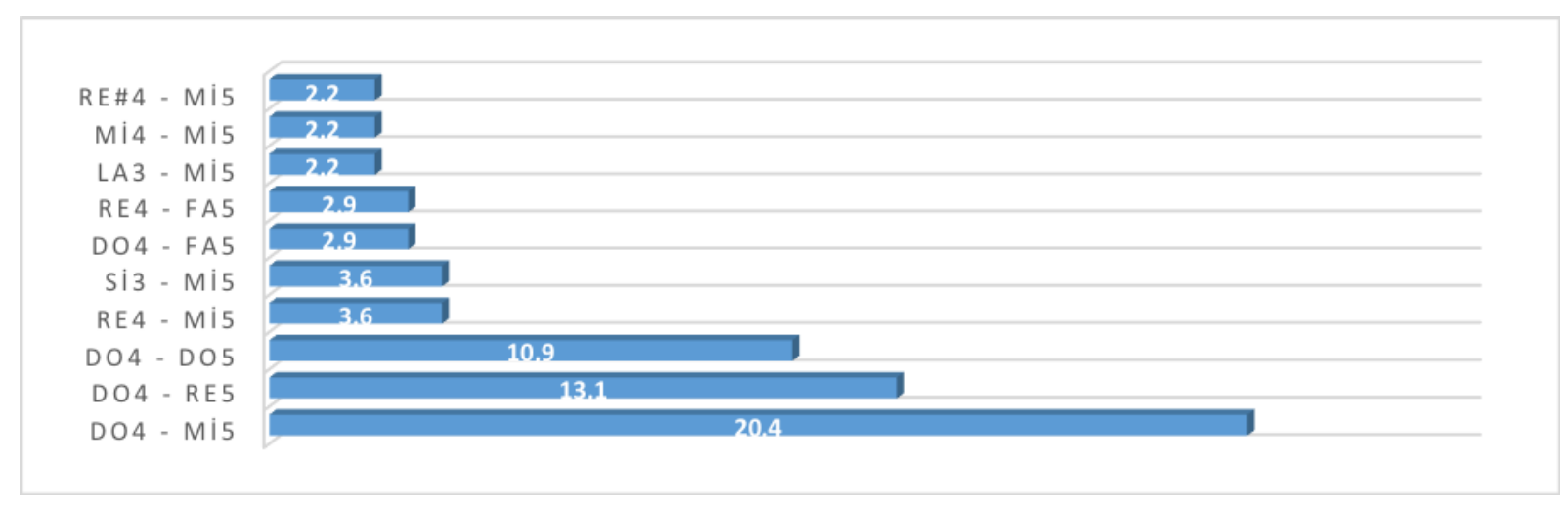

Kitapta bulunan solfejlerin \%20,4'ü (f=28) Do4 - Mi5 aralı̆̆ında, \%13,1’i (f=18) Do4 - Re5 aralığında, \%10,9’u ise Do4 - Do5 aralığında olduğu görülmektedir. Re4 - Mi5 ve Si3 - Mi5 aralıklarındaki solfejlerin \%3,6'lık (f=5) oranlarda, Do4 - Fa5 ve Re4 - Fa5 ses aralığındaki solfejlerin \%2,9'luk (f=4) oranlarda olduğu tespit edilmiştir. Solfejlerin \%2,2'şerlik (f=3) oranlarının La3 - Mi5, Mi4 - Mi5 ve Re\#4 - Mi5 aralığındaki solfejler olduğu görülmektedir.

Aynı kitapta $53 \mathrm{Fa}$ anahtarlı solfej olduğu ve bu solfejlerin 26 farklı ses aralığında olduğu görülmüştür. En yüksek orana sahip ilk 10 solfej grafik 8 'de gösterilmiştir.

Grafik 8. “Corso Facile Di Solfeggio" kitabinda bulunan Fa anahtarl solfejlerin ses aralıklart

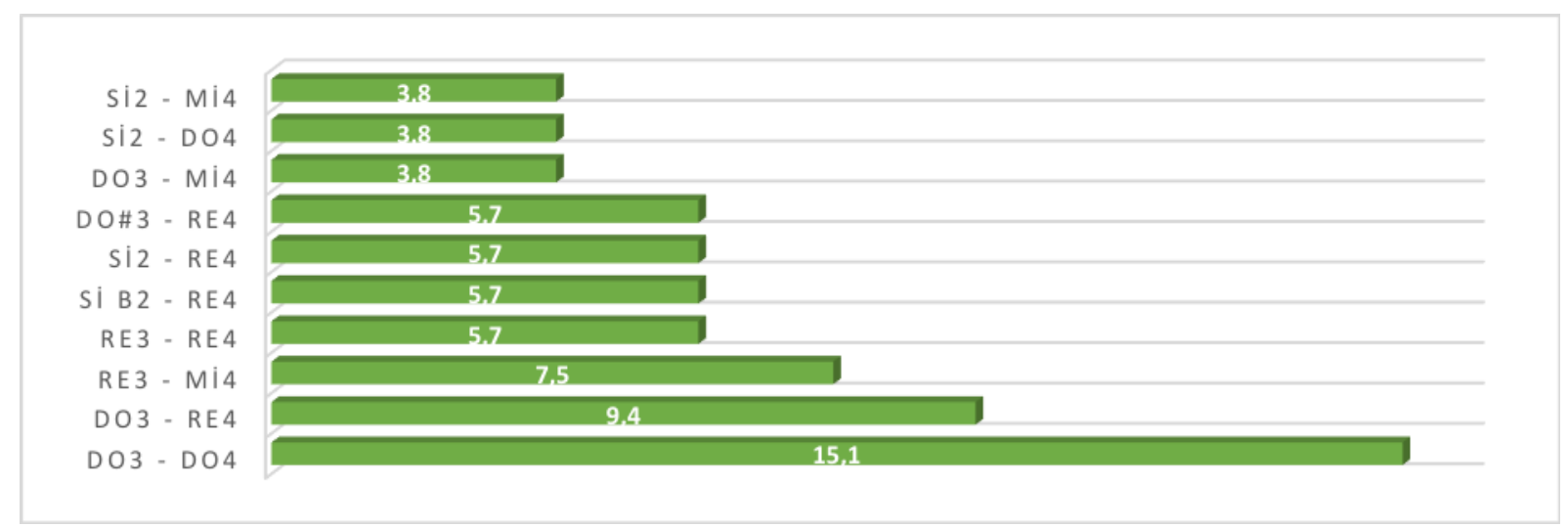

Kitaptaki solfejlerin \%15,1'inin (f=8) Do3 - Do4 aralığında, \%9,4'ünün (f=5) Do3 - Re4 aralığında olduğu, \%7,5'inin ise (f=4) Re3 - Mi4 aralığında olduğu tespit edilmiştir. Re3 - Re4, Sib2 - Re4 ve Si2 - Re4 aralığındaki solfejlerin \%5,7'şerlik (f=3) oranlarda olduğu görülürken, Do3 - Mi4, Si2 - Do4 ve Si2 - Mi4 aralığındaki solfejlerin \%3,8'erlik (f=2) oranlarda olduğu görülmüştür.

Lavignac 1A solfej kitabında 175'i Sol anahtarlı, 29 ise Fa anahtarlı olmak üzere toplam 204 solfej olduğu görülmüş. Ayrıca 34'ü sol anahtarlı solfejlerde, 18'i ise Fa anahtarlı solfejlerde olmak üzere 52 çeşit ses aralığı tespit edilmiştir. Sol anahtarında en yüksek orana sahip ilk 10 ses aralığı grafik 9'da gösterilmiştir 
Grafik 9. “Lavignac 1A” kitabında bulunan Sol anahtarlı solfejlerin ses aralıklart

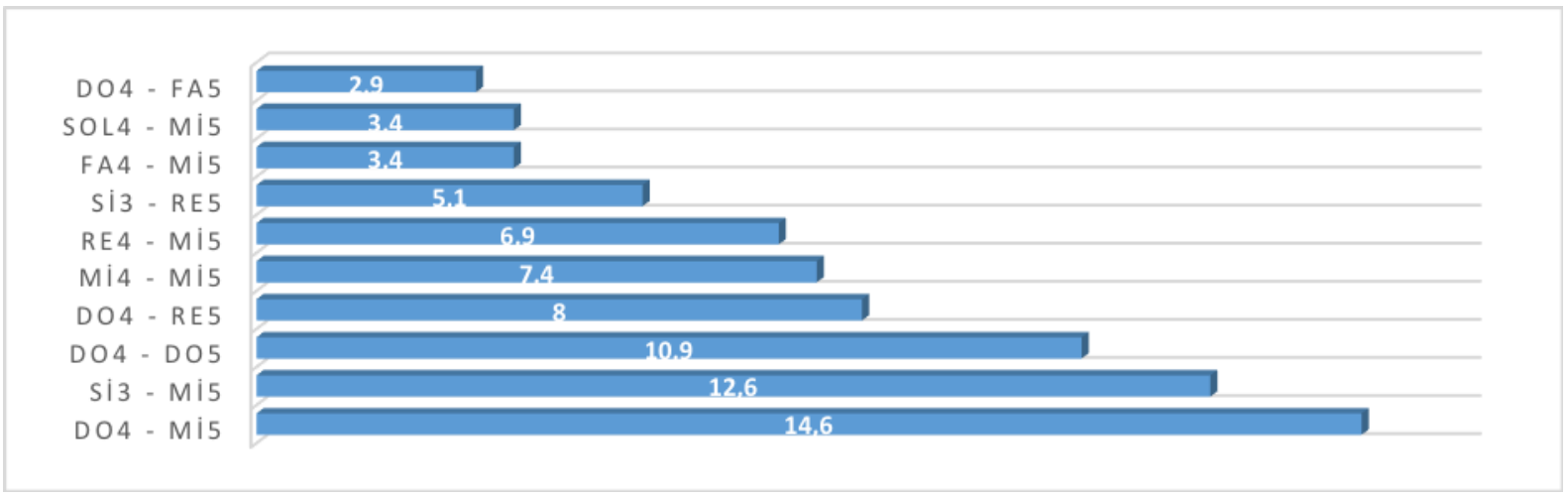

Kitapta bulunan solfejlerin \%14,6'sının (f=28) Do4 - Mi5 aralığında, \%12,6'sının (f=22) \%Si3 - Mi5 aralığında, \%10,9'unun (f=19) Do4 - Do5 aralığında olduğu görülmüştür. Aynı şekilde \%8'inin (f=14) Do4 - Re5 aralığında, \%7,4'ünün (f=13) Mi4 - Mi5 aralığında, \%6,9'unun (f=12) Re4 - Mi5 aralığında ve \%5,1'inin (f=9) ise Si3 - Mi5 aralığında olduğu tespit edilmiştir. Sol4 - Mi5 ve Fa4 - Mi4 aralıklarındaki solfejlerin oranlarının \%3,4 (f=6) olduğu görülürken, Do4 - Fa5 aralığındaki solfejlerin oranlarının \%2,9 (f=5) olduğu görülmüştür.

Lavignac 1A solfej kitabında bulunan 29 Fa anahtarlı solfejin en yüksek orana sahip ilk 10 solfeji grafik 10'da gösterilmiştir.

Grafik 10. "Lavignac 1A” kitabinda bulunan Fa anahtarlı solfejlerin ses araltklart
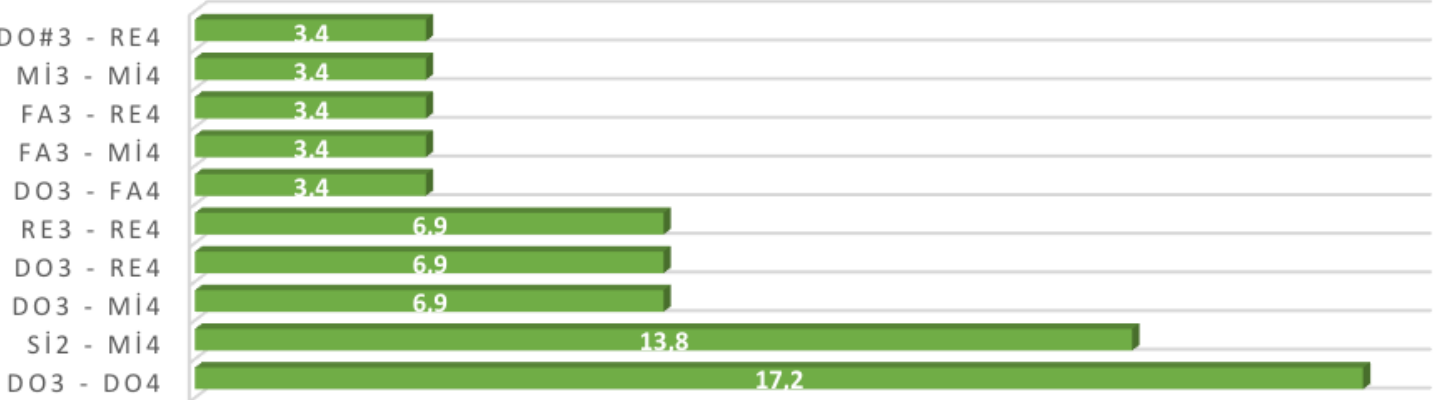

Solfejlerin \%17,2'sinin (f=5) Do3 - Do4 aralığında, \%13,8'inin (f=4) Si2- Mi4 aralığında olduğu görülmüştür. Si3 - Re4, Do3 - Re4, Re3 - Re4 ses aralıklarının \%6,9'arlık (f=2) oranlarda olduğu görülürken, Do3 - Fa4, Fa3 - Mi4, Fa3 - Re4, Mi3 - Mi4 ve Do\#3 - Re4 ses aralıklarının \%3,4'erlik (f=1) oranlarda olduğu görülmüştür. Ayrıca kalan 9 solfejin ses aralıklarının da \%3,4'erlik oranlara sahip olduğu tespit edilmiştir.

Lavignac serinin başlangıç düzeyindeki ikinci kitabı olarak görülen Lavignac 1B solfej kitabında 142'si Sol anahtarlı, 26’sı Fa anahtarlı olmak üzere toplam 168 solfej olduğu görülmüştür. Ayrıca Sol anahtarlı 142 solfejin 45 çeşit ses aralığından, $26 \mathrm{Fa}$ anahtarlı solfejin 15 çeşit ses aralığından oluştuğu tespit edilmiştir.

Kitapta bulunan Sol anahtarlı solfejlerden en yüksek orana sahip ilk 10 solfej, grafik 11'de gösterilmiştir. 
Grafik 11. "Lavignac 1B” kitabinda bulunan Sol anahtarlı solfejlerin ses araliklart

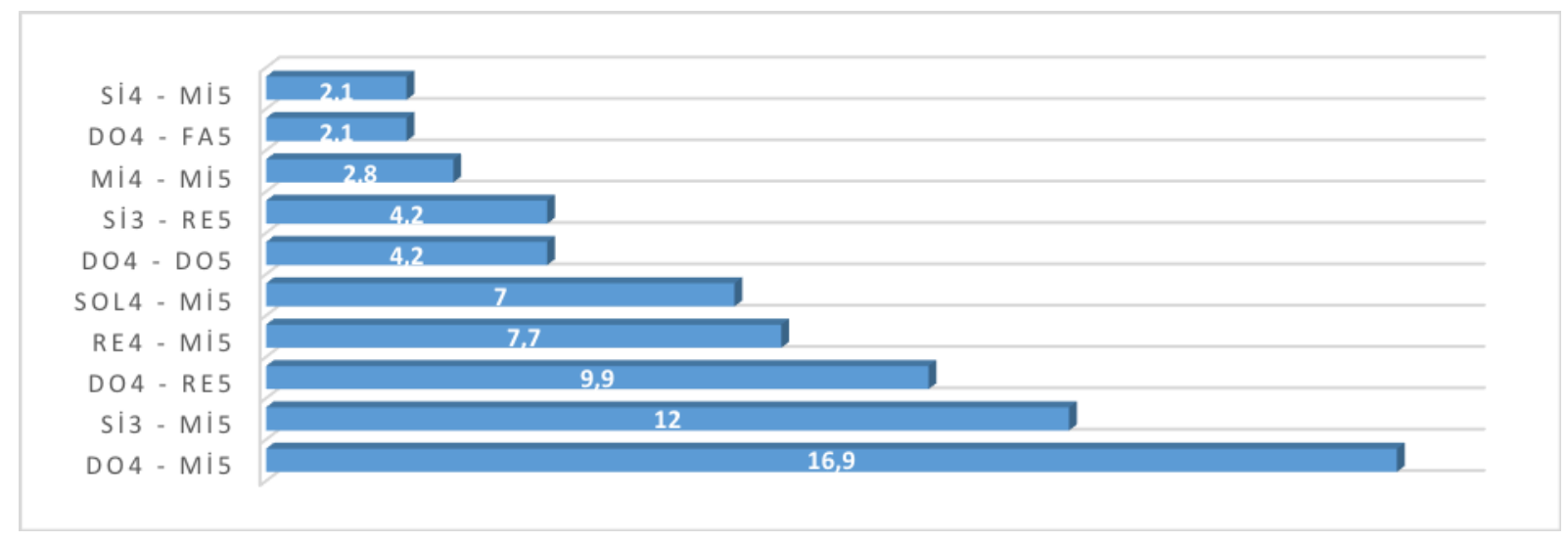

Solfejlerin \%16,9'u (f=24) Do4 - Mi5 ses aralığında, \%12'si (f=17) Si3 - Mi5 ses aralığında, \%9,9'u (f=14) Do4 - Re5 ses aralığında, \%7,7'si (f=11) Re4 - Mi5 ses aralığında ve \%7'si (f=10) Sol4 - Mi5 ses aralığında olduğu tespit edilmiştir. Si3 - Re5 ve Do4 - Do5 ses aralığındaki solfejler \%4,2'şerlik (f=6) oranlarda olduğu görülürken, solfejlerin \%2,8'inin (f=4) Mi4 - Mi5 aralığında olduğu görülmüştür. Ayrıca Si4 - Mi5 ve Do4 - Fa5 ses aralığındaki solfejlerin \%2,1'erlik ( $\mathrm{f}=3$ ) oranlarda olduğu tespit edilmiştir.

Lavignac 1B solfej kitabında bulunan 26 Fa anahtarlı solfejin en yüksek orana sahip ilk 10 solfeji grafik 12 'da gösterilmiştir.

Grafik 12. "Lavignac 1B" kitabında bulunan Fa anahtarlt solfejlerin ses aralıklart

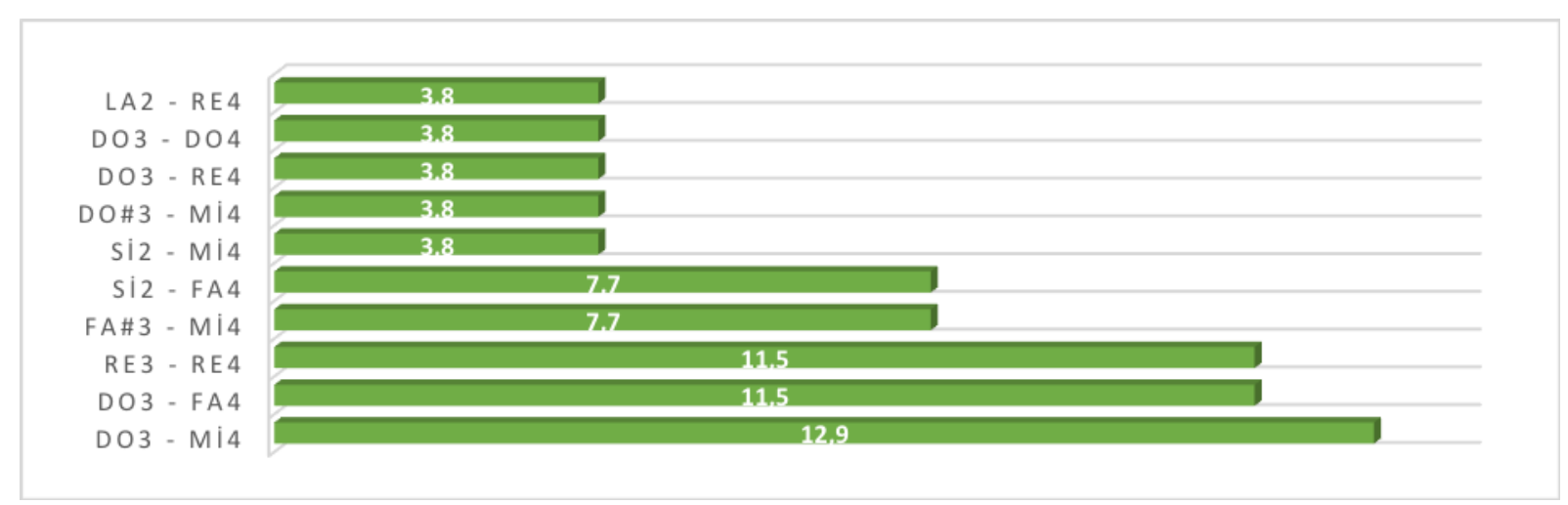

Kitapta bulunan solfejlerin \%12,9’u (f=5) Do3 - Mi4 aralığında olduğu görülürken, \%11,5'erlik (F=3) oranlarda Do3 - Fa4 ve Re3 - Re4 ses aralığındaki solfejlerin olduğu görülmüştür. Fa\#3 - Mi4 ve Si2 - Fa4 ses aralığındaki solfejlerin \%7,7 (f=2) oranında olduğu görülürken, Si2 - Mi4, Do\#3 - Mi4, Do3 - Re4, Do3 - Do4 ve La2 - Re4 ses aralığındaki solfejlerin \%3,8'lik (f=1) oranlarda olduğu görülmüştür.

\section{Sonuç ve Öneriler}

Araştırmada Edouard Batiste tarafında yazılan "Petit Solfege", Frédéric Boissiére tarafindan yazılan "Solfége Elémentaire", Gaetano Nava tarafından yazılan "Elementary Solfeggi for Medium Voice Op.9”, Ettore Pozzoli tarafından hazırlanan Corso Facile di Solfeggio ve Albert Lavignac tarafindan yazılan Solfége des Solféges 1A ve 1B numaralı solfej kitapları içeriğindeki konular, ölçü birimi, ton, anahtar ve ses aralığı açısından incelenmiştir. İnceleme sonucunda şu sonuçlara ulaşılmıştır; 
İncelenen 8 solfej kitabında ortak konular olduğu kadar, hem konu hem de ortak konuların içeriği noktasında ayrıştığı görülmüştür. "Petit Solfege” kitabında diğer kitaplardan farklı olarak modülasyon, Anarmonikler ve Sol - Fa anahtarlarına yönelik dizi çalışmalarının olduğu görülürken, 3/2’lik gibi farklı ölçü biriminde çalışmalar ve Solb majör, Reb majör, Fa minör vb. tonlarda çalışmaların olduğu görülmüştür. Kitapta ayrıca disonans ve konsonans akorlar ve aralıklar konusuna da değinildiği tespit edilmiştir. "Solfége Elémentaire” solfej kitabında Fa anahtarına yönelik çalışmaların olmadığı görülürken, içerik olarak diğer solfej kitaplarından farklılaşmadığı tespit edilmiştir. Ayrıca kitapta 3/2, 4/2, 5/4, 6/4, 2/16, 4/16 gibi nadir kullanılan ölçüler ile ilgili solfejlerin olduğu görülmüştür. "Elementary Solfeggi for Medium Voice Op.9” solfej kitabında tonalite, nüans terimleri, Fa anahtarı gibi konuların olmadığı görülürken, tonalite ile ilgili bilgilerin solfejlerin yapısından öğrenilebileceği görülebilir. “Corso Facile di Solfeggio" solfej kitabında diğer kitaplardan farklı olarak senkop, üçleme, nüans ve süsleme gibi konulara yönelik solfejlerin olmadığı görülürken, öğrenilen konuları pekiştirme amaçlı genel alıştırma sayısının diğer solfej kitaplarına nazaran daha fazla olduğu görülmüştür. Ayrıca 2'nci ve 3'üncü oktavlar ile küçük oktav gibi nota yazılırken ek çizgi kullanılması gereken notaların öğretilmesi ve pekiştirilmesi amacıyla bestelenmiş olan solfejlerin olduğu görülmektedir. "Solfége des Solféges 1A” ve "Solfége des Solféges 1B” kitaplarının içeriğindeki konular noktasında aynı olduğu ama tonalite konusunda "Solfége des Solféges 1B" solfej kitabında 1A kitabı tonalite konusunda yer alan tonlara ek olarak La majör, Fa\# minör, Mi bemol majör ve Do minör tonlarının olduğu görülmüştür.

Bu bağlamda solfej kitaplarında; aralık, ölçü, tonalite, senkop, üçleme, bağ, nüans ve tekrar işaretleri gibi konuların ortak olduğu görülürken konuların içerik olarak ayrışabileceği sonucuna ulaşılmıştır. Ayrıca bazı kitaplarda $\mathrm{Fa}$ anahtarına yönelik çalışmaların olmadığı da araştırmada elde edilen başka bir sonuç olarak görülebilir.

"Petit Solfege" ve "Solfége Elémentaire" solfej kitaplarında 10, "Elementary Solfeggi for Medium Voice Op.9” solfej kitaplarının birinci kitabında 8, ikinci ve üçüncü kitaplarında 6, "Corso Facile di Solfeggio” solfej kitabında 9, "Solfége des Solféges 1A" ve "Solfége des Solféges 1B” solfej kitaplarında 6 farklı ölçü birimi olduğu görülmüştür. Ölçü birimi açısından bakıldığında en geniş yelpazeye sahip olan kitapların "Petit Solfege" ve "Solfége Elémentaire" solfej kitapları olduğu sonucuna ulaşılmıştır. "Corso Facile di Solfeggio" solfej kitabı dışındaki tüm solfej kitaplarında 4/4'lük ölçü biriminde yazılan solfejlerin çoğunlukta olduğu görülürken “Corso Facile di Solfeggio" solfej kitabında 2/4'lük ölçü biriminin çoğunlukta olduğu sonucuna ulaşılmıştır.

Tonlara göre dağılıma bakıldığında; "Petit Solfege" solfej kitabında 22, "Solfége Elémentaire” solfej kitabında 12, "Elementary Solfeggi for Medium Voice Op.9” solfej kitaplarının birinci kitabında 9, ikinci kitapta 8 ve üçüncü kitapta 10, "Corso Facile di Solfeggio" solfej kitabında 14, "Solfége des Solféges 1A" ve "Solfége des Solféges 1B” solfej kitaplarında 10 farklı ton olduğu görülmüştür. Çalışma grubunda yer alan tüm solfej kitaplarında Do majör tonundaki solfejlerin büyük oranda çoğunlukta olduğu görülmüştür. "Petit Solfege" solfej kitabı ton anlamında en geniş yelpazeye sahip olan solfej kitabı olduğu sonucuna ulaşılmıştır. Başlangıç düzeyi solfej kitaplarında nota, aralık, entonasyon ve farklı tartımlara yönelik çalışmaların olduğu düşünüldüğünde en uygun tonun Do majör olabileceği, çünkü öğrencinin sadece öğretilmesi gereken hedefe odaklanmasının sağlıklı olacağı düşünülmektedir.

Çalışma grubunda yer alan "Solfége Elémentaire” ve "Elementary Solfeggi for Medium Voice Op.9” solfej kitapları dışındaki tüm kitaplarda hem Sol hem de Fa anahtarlı solfejlerin mevcut olduğu görülürken, diğer iki 
kitapta sadece Sol anahtarlı solfejlerin olduğu görülmüştür. Hem Sol hem de Fa anahtarlı solfej kitaplarında ise Sol anahtarlı solfejlerin çoğunlukta olduğu sonucuna ulaşılmıştır.

Solfej kitaplarında yer alan solfejlerin ses aralıkları incelenirken oktav farkından ötürü Sol anahtarlı solfejler ve Fa anahtarlı solfejler ayrı ayrı incelenmiştir. Sol anahtarlı solfejler incelendiğinde; "Petit Solfege" solfej kitabında en pes sesin Sol\#3, en tiz sesin ise Fa\#5 olduğu görülmüştür. Ayrıca solfejlerin çoğunun (\%16,9) Si3 Re5 aralığında olan solfejler olduğu sonucuna ulaşılmıştır. "Solfége Elémentaire” solfej kitabında ise en pes sesin Do4, en tiz sesin ise Mi5 olduğu tespit edilmiş, Do4 - Re5 aralığındaki solfejlerin çoğunluğu $(\% 27,3)$ oluşturduğu sonucuna ulaşılmıştır. "Elementary Solfeggi for Medium Voice Op.9” kitabı üç farklı kitap ayrı ayrı incelenerek ele alınmıştır. Birinci kitapta en pes ses La3, en tiz ses Sol5, ikinci kitapta en pes sesin Sib3, en tiz sesin ise Fa\#5, üçüncü kitapta ise en pes ses La3, en tiz ses ise Sol5 olarak tespit edilmiştir. Serinin iki kitabında solfejlerin büyük çoğunluğunun Do4 - Fa5 aralığında olduğu tespit edilirken bu oran birinci kitapta \%24, ikinci kitapta \%33,3 olarak tespit edilmiştir. Üçüncü kitaptaki solfejlerin eşit oranlarla $(\% 11,8)$ Si3 - Fa5, Re4 - Fa5, Do4 - Sol5 ve Do\#4 Fa5 aralıklarında olduğu sonucuna ulaşılmıştır. "Corso Facile di Solfeggio" solfej kitabında yer alan solfejlerin çoğunluğunun $(\% 20,4)$ Do4 - Mi5 aralığında olduğu görülürken en pes sesin Sol3, en tiz sesin ise kitapta ikinci ve üçüncü oktava yönelik nota çalışmaları olduğu için Sol5 olduğu tespit edilmiştir. "Solfége des Solféges 1A" ve "Solfége des Solféges 1B” solfej kitaplarındaki solfejlerin çoğunluğunun (1A için \%14,6, 1B için \%16,9) Do4 Mi5 aralığında olduğu tespit edilmiştir. "Solfége des Solféges 1A" kitabındaki en pes ses Si3, en tiz ses ise Fa5 olarak tespit edilirken, "Solfége des Solféges 1B” kitabında ise en pes ses Sib3, en tiz ses ise Sol5 olarak tespit edilmiştir.

Solfej kitaplarında yer alan Fa anahtarlı solfejler incelendiğinde; "Petit Solfege" kitabında yer alan solfejlerin çoğunluğunun $(\% 36,4) \mathrm{Si} 2$ - Re4 aralığında olduğu tespit edilmiştir. Fa anahtarlı solfejlerde en pes sesin Si2, en tiz sesin ise Re4 olduğu görülmüştür. "Corso Facile di Solfeggio” solfej kitabında en pes ses Sol2, en tiz ses ise Mi4 olduğu, Fa solfejlerin çoğunluğunun $(\% 15,1)$ Do3 - Do4 aralığında olduğu görülmüştür. "Solfége des Solféges 1A" solfej kitabında yer alan Fa anahtarlı solfejlerin çoğunun $(\% 17,2)$ Do3 - Do4 aralığında olduğu tespit edilirken, Fa anahtarlı solfejlerde en pes sesin Si2, en ince sesin Mi4 olduğu görülmüştür. "Solfége des Solféges 1B” solfej kitabında en pes sesin Si2, en tiz sesin ise Fa4 olduğu görülürken Fa anahtarlı solfejlerin çoğunun $(\% 12,9)$ Do3 - Mi4 ses aralığında olduğu sonuçlarına ulaşılmıştır.

Araştırmada elde edilen sonuçlardan yola çıkılarak şu genellemelere ulaşılmaktadır;

- Başlangıç düzeyi solfej kitaplarının konu noktasında benzerlikler gösterdiği ama konuların içeriği yönünden farklılıklar gösterebileceği,

- Başlangıç düzeyi solfej kitaplarının eğitimin ilkeleri ışığında kolaydan zora, basitten karmaşığa doğru sıralandığı,

- Başlangıç düzeyi solfej kitaplarında basit ölçü olarak sınıflandırılan 2/4, 3/4 ve 4/4 gibi ölçü birimlerinin kullanıldı̆̆

- Başlangıç düzeyi solfej kitaplarında genellikle donanımında hiçbir değiştirici işaretin bulunmadığı Do majör ve La minör tonlarının kullanıldığı,

- Birden fazla anahtarın öğretiminin yapıldı̆̆ı solfej kitaplarında genellikle Sol anahtarlı solfejlerin çoğunlukta olduğu hatta bazı solfej kitaplarının sadece Sol anahtarlı solfejlerden oluştuğu sonuçlarına ulaşılmıştır. 
Araştırmada yapılan literatür taraması, solfej kitaplarının incelenmesi ve analiz edilmesi ışığında elde edilen sonuçlara göre;

- Başlangıç düzeyi solfej kitaplarında tonalite ve ölçü birimi çeşitliğinin arttırılması müzik eğitimi alan öğrencilerin kısa sürede farklı ton ve ölçü birimlerini öğrenmesi adına faydalı olacağı düşünülmektedir.

- Başlangıç düzeyi solfej kitaplarında Sol anahtarına yönelik çalışmaların yeterli ölçüde olduğu görülürken Fa anahtarına yönelik çalışmaların görece az olduğu tespit edilmiştir. Fa anahtarlı solfejlerin niceliklerinin arttırılması hatta viyola ve viyolonselde kullanılan üçüncü veya dördüncü çizgi Do anahtarlarının da eklenmesi, öğrencilerin diğer anahtarları tanıması noktasında faydalı olacaktır.

- İlerleyen dönemlerde yazılacak olan solfej kitaplarında teorik bilgilerin yazılı olarak ifade edilmesi ve öğrencilerin o teorik bilgiler ışığında solfej çalışmaları yapmaları, teorinin güçlenmesi adına faydalı olacaktır.

- Çoksesliliğin pekiştirilmesi ve ses entonasyonunun oturması adına solfejlerin piyano eşliklerinin yazılması veya piyano eşlikli solfej kitaplarının tercih edilmesinin faydalı olacağı düşünülmektedir.

- Ülkemizde yazılacak solfej kitaplarının tonal ezgiler kadar makamsal ezgilere de yer verilmesi, hatta makamlara ve usullere yönelik teorik bilgilerin verilmesi, öğrencilerin Türk müziğini tanımaları açısından faydalı olacaktır.

- $\quad$ Bu çalışmaya paralel olacak şekilde; başlangıç düzeyinde yazılmış olan farklı solfej kitaplarının, ileri seviye solfej kitaplarının ve Türk müziğine yönelik makamsal solfej kitaplarının hem tanıtılması hem de eğitime uygunluğu açısından uzmanlar tarafından incelenmesi önerilmektedir.

\section{Kaynakça/References}

Aydoğan, S. (1998). Müzik öğretmeni yetiştiren kurumlarda müziksel işitme okuma öğretimi (Yayımlanmamış Doktora Tezi), Gazi Üniversitesi Fen Bilimleri Enstitüsü, Ankara.

Baş, E. (2015). Ezgi kalıpları kullanılarak başlangıç solfej ve dikte eğitimine yönelik bir model üzerine araştırma (Yayımlanmamış Doktora Tezi), İnönü Üniversitesi Sosyal Bilimler Enstitüsü, Malatya.

Best, J. W., \& Kahn, J. V. (2017). Eğitimde Araştırma Yöntemleri, Nitel Araştırma Bölümü (Çev. Mustafa Durmuşçelebi), (Edt. Onur Köksal). Konya: Dizgi Ofset.

Büyüköztürk, Ş., Akgün, Ö. E., Demirel, F., Karadeniz, Ş., \& Çakmak, E. K. (2015). Bilimsel Araştırma Yöntemleri. Ankara: Pegem Akademi.

Erol, T. (2019). Ülkemizdeki üç konservatuarda kullanılan solfej materyallerinin incelenmesi (Yayımlanmamış Yüksek Lisans Tezi), Mersin Üniversitesi Güzel Sanatlar Enstitüsü, Mersin.

Ertok, N. (1994). Cumhuriyet döneminde Türkiye'de günümüze kadar yazılmış solfej kitaplarının incelenmesi (Yayımlanmamış Yüksek Lisans Tezi), Marmara Üniversitesi Fen Bilimleri Enstitüsü. İstanbul.

Fenmen, M. (1997). Müzikçinin El Kitabı. Ankara: Müzik Ansiklopedisi Yayınları.

İlkay, H. (2004). Türkiye'deki eğitim fakülteleri güzel sanatlar eğitimi bölümü müzik öğretmenliği anabilim dalı müzik teorisi ve işitme eğitimi dersinde okutulan solfej kitaplarının müzik eğitimine uygunluğu açısından incelenmesi (Yayımlanmamış Yüksek Lisans Tezi), Gazi Üniversitesi Eğitim Bilimleri Enstitüsü, Ankara.

Kılıçarslan, A. (1995). Geleneksel Türk müziğinde solfej ĕğitimi (Yayımlanmamış Doktora Tezi), Selçuk 
Üniversitesi Fen Bilimleri Enstitüsü, Konya.

Ozan, E., Gürpınar, E., Zahal, O., Yıldız, D., \& Adıgüzel, A. (2017). Çoksesli solfej eğitiminde kullanılan Solfege des Solfeges kitaplarının içerik analizi. Inönü Üniversitesi Sanat ve Tasarım Dergisi, 7(16), 158-174.

Özçelik, S. (2010). Müzikal Dikte ve Solfej. İzmir: Lamineks Matbaacılık.

Özgür, Ü., \& Aydoğan, S. (2015). Müziksel İşitme Okuma Ĕgitimi ve Kuram I. Yyy: Arkadaş Yayınları.

Ünlü, L. (2019). Solfej eğitiminde görsel ve işitsel uygulamaların müziksel okuma becerisine etkisi (Yayımlanmamış Doktora Tezi). İnönü Üniversitesi Eğitim Bilimleri Enstitüsü, Malatya.

Yazan, E. İ. (2007). Konservatuvar şarkıcılık lisans programlarında solfej ĕgitiminde izlenen kaynak ve yöntemlerin analizi (Yayımlanmamış Yüksek Lisans Tezi), Başkent Üniversitesi Sosyal Bilimler Enstitüsü, Ankara. 